\title{
José Álvarez (1723-1800), maestro mayor de obras del Arzobispado de Sevilla
}

\author{
José Manuel Higuera Meléndez \\ Doctor Arquitecto
}

\begin{abstract}
Resumen: José Álvarez fue uno de los más activos maestros mayores de obras de la archidiócesis sevillana del XVIII. Contemporáneo de Pedro de Silva, Ambrosio y Antonio de Figueroa y Fernando Rosales, alternó los encargos del Cabildo eclesiástico con los del Arzobispado, siendo estos últimos los que le otorgaron mayor prestigio. Basta citar algunos de los templos que construyó (Moguer, Santa Cruz de Écija, San Bernardo de Sevilla, Aznalcóllar,...) para comprender la magnitud de sus realizaciones. Sorprendentemente, su obra no había merecido aún la edición de una monografía, debido quizá a la falta de noticias biográficas más allá de la de su origen onubense. Este trabajo pretende subsanar dicho vacío, documentando por vez primera su nacimiento y fallecimiento, su reducido círculo familiar, su autoría sobre relevantes obras eclesiales y repasando cronológicamente su actividad profesional. Todo ello para poner en valor la figura de uno de los grandes nombres de la arquitectura tardobarroca sevillana.
\end{abstract}

\begin{abstract}
José Álvarez was one of the most active master-builders to the Arbishopric of Seville along the XVIII century. He was contemporary to Pedro de Silva, Ambrosio and Antonio de Figueroa, Fernando Rosales, and undertook orders of the ecclesiastical Cabildo combaning them with the ones coming from the Archbishopric, being the latter ones that provided him greatest prestige. Just mentioning some of the temples he built up (Moguer, Santa Cruz de Écija, San Bernardo de Sevilla, Aznalcóllar, ...) is enough to make us understand the magnitude of his achievements. Surprisingly, his work had not yet been honoured with a published monography, due perhaps to the lack of biographical news beyond that the one related to his Huelva's origins. This work seeks to overcome this gap by documenting for the first time his birth and death, his little family intimacy, his authorship on relevant ecclesial works and finally to chronologically review his professional workship. All this to put in value the figure of one of the greatest names in late sevillian-baroque architecture.
\end{abstract}




\section{INTRODUCCIÓN: LA FIGURA DE JOSÉ ÁLVAREZ EN EL CONTEXTO DE LA ARQUITECTURA DIECIOCHESCA SEVILLANA}

A lo largo del siglo XVIII, alrededor de una veintena de maestros alarifes trabajaron proyectando obras para la Archidiócesis de Sevilla, aunque no todos ostentaron oficialmente la maestría mayor de la Dignidad Arzobispal. Entre los más destacados figuran José y Silvestre Tirado, Diego Antonio Díaz, Pedro y Vicente de San Martín, Tomás José Zambrano, Pedro de Silva, Ambrosio y Antonio de Figueroa, José Álvarez, Fernando Rosales, José Echamorro y Santiago de la Llosa, algunos de los cuales tuvieron a su cargo las intervenciones edilicias de otras instituciones religiosas y civiles de la ciudad. Fue el caso de José y Silvestre Tirado, Diego Antonio Díaz, Tomás José Zambrano y José Álvarez, maestros mayores del Cabildo eclesiástico, y de José Echamorro, maestro mayor de obras del Ayuntamiento hispalense. Cargo este último que también compatibilizaron Pedro de San Martín y Tomás José Zambrano.

Por otro lado, el hecho de producirse el paso del Barroco al Neoclasicismo durante el lento discurrir del XVIII, tuvo su reflejo en la nómina de maestros mayores que trabajaron al servicio de la archidiócesis, más o menos cercanos en cada caso a los postulados de uno u otro estilo. Pero también quedó plasmado en el recorrido artístico de algunos de ellos que, partiendo de un barroquismo exacerbado, atemperaron el gusto por la ornamentación superflua y excesiva, evolucionando hasta un clasicismo acomodado a la tradición artística vernácula ${ }^{1}$.

En cualquier caso, y como ha quedado de manifiesto por la relación de nombres antedicha, la archidiócesis contó con los más reputados alarifes, nacidos o establecidos en la ciudad de Sevilla, en el cargo de maestro mayor de obras del arzobispado, nombramiento muy apetecido por el prestigio profesional que otorgaba a quien lo ostentaba, por el respeto que hacía infundir hacia éste entre sus propios colegas y sin duda por la posibilidad que significaba de legar una obra artística perdurable en el tiempo. Y aunque la designación como maestro mayor de la archidiócesis, ya fuera de albañilería o de carpintería, significaba contar a partir de entonces con unos ingresos seguros que daban para vivir sin ostentaciones, se dio el caso de maestros que murieron sumidos en la pobreza ${ }^{2}$.

La instauración en esta centuria de un "estilo" propio y característico de las intervenciones constructivas del Arzobispado de Sevilla, que se puede denominar b"arroco diocesano dieciochesco", debe sus fundamentos al hispalense Diego Antonio Díaz (1667-1748), máximo responsable de la arquitectura diocesana entre 1705 y 1741, período durante el que llevó a cabo numerosas obras para la archidiócesis, si bien su producción artística en cuanto al número de iglesias trazadas de

Este fue el caso, por ejemplo, de Antonio de Figueroa.

Como le ocurrió a Tomás José Zambrano. 
nueva planta se refiere apenas supera la decena ${ }^{3}$. Sería a partir del 1 de noviembre de 1755, como consecuencia de los efectos del Terremoto de Lisboa, cuando se acometería de manera generalizada la renovación del patrimonio edilicio eclesiástico mediante la intervención de otros maestros mayores. Contribuyeron de manera especial a la consolidación del barroco diocesano, aquellos que tuvieron una mayor actividad constructiva y que sobre todo, realizaron los más notables edificios de la segunda mitad del XVIII, no siendo otros que los sevillanos Pedro de Silva (1710-1784), Ambrosio de Figueroa (1702-1775) y su hijo Antonio (1733-1793), si bien este último intentó adaptarse progresivamente al nuevo movimiento clasicista que impulsaba la Academia. De igual manera, habría que reivindicar también la faceta barroca del maestro onubense José Álvarez, contemporáneo y colaborador de Antonio de Figueroa, que partiendo de la misma tradición artística que éste y asumiendo los mismos consolidados planteamientos tipológicos, abrazó en general los postulados academicistas en la formalización de sus obras diocesanas ${ }^{4}$. En palabras del profesor Sancho Corbacho, Álvarez es "el arquitecto menos influido por estas normas académicas", pues sigue la tradición sevillana, "aunque el neoclasicismo haya hecho presa en él en el sentido de evitar toda clase de ornato en sus obras" ${ }^{\prime \prime 5}$.

Dicho historiador otorga a José Álvarez un papel relevante en su monumental estudio sobre la arquitectura barroca sevillana, dando a conocer sus proyectos de San Pedro de Jerez, Santa Cruz de Écija, San Bernardo de Sevilla, Aznalcóllar, Campofrío y Santa Ana la Real ${ }^{6}$. Sin embargo, Sancho Corbacho no llega a ofrecer dato alguno sobre sus comienzos ni sobre su cronología vital, salvo que en 1785 "declaró tener sesenta años de edad"7. Sería el profesor Falcón Márquez quien daría a conocer el origen onubense del alarife, expuesto en su carta de examen para

3 Casi todas las iglesias de nueva planta de Diego A. Díaz documentadas le fueron encargadas por congregaciones conventuales y hermandades. Además, construyó un templo monumental para el arzobispo D. Luis de Salcedo y Azcona, Ntra. Sra. de Consolación, de Umbrete, considerada su obra maestra (1725-1733), y proyectó dos iglesias parroquiales para la diócesis hispalense, San Miguel Arcángel, de Jabugo (1722) y la Purísima Concepción, de las Navas de la Concepción (1727), las cuales presentan ya las características comunes que harán reconocible al barroco diocesano de la segunda mitad del setecientos.

4 Las influencias mutuas entre Antonio de Figueroa y José Álvarez hacen muy difícil distinguir los elementos que se deben a cada uno, en los diversos templos en los que intervinieron ambos maestros.

5 Quiere decir el historiador que José Álvarez estaba menos influido por la Academia que Lucas Cintora, José Echamorro, Ignacio Tomás y Fernando Rosales, los cinco maestros que conforman el capítulo de su obra sobre el barroco sevillano titulado "Los arquitectos neoclásicos y la influencia de la Academia madrileña" (Antonio SANCHO CORBACHO: "Arquitectura barroca sevillana del siglo XVIII", CSIC, Madrid, 1952, Reed. 1984, p. 249-263). De todas formas, la moderación ornamental, que no ausencia, no puede usarse por sí sola para argumentar la pertenencia de José Álvarez a la corriente neoclásica o, por mejor decir, academicista. Debiendo fundamentarse ésta en el ponderado clasicismo no exento de cierto énfasis barroco que muestra su obra, explicitado mediante la coexistencia de elementos distintivos de la influencia académica, como triglifos y metopas, en interiores ornamentados con yeserías y labradas portadas con la utilización preferente de la columna.

6 No obstante, el análisis de la documentación diocesana deja claro que las iglesias de Campofrío y Santa Ana la Real no se pueden atribuir a José Álvarez, como se verá más adelante.

7 En realidad, Álvarez declaró ser "de hedad de mas de sesenta años" (AGAS, Justicia, Pleitos ordinarios, Leg. 12215, 29.Oct.1785). 
la maestría $(1763)^{8}$, en la que afirmó tener treinta y dos años, lo cual permitía datar su nacimiento hacia 1731. Diferentes noticias referidas al maestro, dadas a conocer tanto en artículos especializados como en publicaciones dedicadas a la arquitectura eclesial dieciochesca en ámbitos territoriales concretos ${ }^{9}$, han ido revelando nuevas atribuciones y encuadrando en el contexto artístico del momento la obra de José Álvarez que, posiblemente por la falta de datos biográficos, no ha merecido aún la edición de una monografía. El trabajo que aquí se presenta pretende subsanar dicha anomalía historiográfica, puesto que en el transcurso de esta investigación se han localizado algunos relevantes documentos inéditos que aportan novedosos datos sobre la vida y obra de este notable artista. De ellos, los más significativos son la partida de su bautizo -que confirma su nacimiento en la villa de Huelva, permitiendo fijar con más precisión su período de actividad-, las de su matrimonio y entierro y su testamento.

\section{ORIGEN Y FORMACIÓN ONUBENSES DEL MAESTRO Y SU ESTABLECIMIENTO EN SEVILLA. PRIMEROS TRABAJOS PARA LA ARCHIDIÓCESIS}

En realidad, José Álvarez de Mesa fue bautizado el 31 de octubre de 1723 en la iglesia parroquial de San Pedro de Huelva, villa en la que había nacido el 25 de dicho mes y de la cual eran vecinos sus padres, el maestro albañil Juan Álvarez y su mujer Paula de Mesa ${ }^{10}$. Como se verá, este adelanto de ocho años respecto de su fecha de nacimiento hasta ahora aceptada se ajusta con mayor lógica a los períodos de aprendizaje y uso del oficio que proporciona el alarife en su examen para la obtención de la maestría.

Hijo y nieto de maestros albañiles locales, el joven José Álvarez entraría de aprendiz con su primo José Clemente Álvarez a la edad de trece o catorce años, instruyéndose en el oficio a su lado durante más de cinco, lo que significa que comenzaría a trabajar por su cuenta en Huelva en los primeros años de la década de 1740.

Algún tiempo después se trasladó a Sevilla, estableciéndose en la collación del Salvador. Allí conocería a la que había de ser su única esposa, María Vicenta Sanguino, con la cual contrajo matrimonio el 8 de septiembre de 1750 a la edad

8 Teodoro FALCÓN MÁRQUEZ: "Pedro de Silva, arquitecto andaluz del siglo XVIII", Diputación de Sevilla, 1979, p. 20.

9 Teodoro FALCÓN MÁRQUEZ: "Documentos para el estudio de la arquitectura onubense", Huelva, 1977, p. 22. También del mismo autor: "Iglesias de la sierra de Cádiz", Cádiz, 1983, p. 19-20.

10 Partida de bautismo de José Álvarez. APSPH, Libro 4 de bautismos, Fol. 241r. Inédito:

"En la Villa de Huelba en treinta y Un dias del mes de Nobe (es octubre) de mill Settos. Y Veinte Y tres años Yo $D^{n}$. Fran ${ }^{\text {co }}$. de torres Y esquibel Presbitero Y de lisensia de $D^{n}$. Juan del Castillo Cura de las Yglecias Parroquiales desta dicha Villa Exorsise, Cathequisse Y baptise a Joseph hijo Lexitimo de Juan Alvares Y de Paula de Messa su lexitima muger, nacio a Veinte Y sinco deste dicho mes fueron sus Padrinos Fran ${ }^{c}$. Vaes Y thomasa Alvares todos naturales Y Vecinos desta dicha Villa En fee de lo qual lo firme Y les adverti la cognasion Spiritual Y obligacion de Enseñarle la doctrina Xptiana fh ${ }^{\circ}$. Ut Supra $="$. 
de veintiséis años ${ }^{11}$, siendo velados el 26 de enero de 1752. Desafortunadamente, esta rama de la familia de alarifes se vio interrumpida, pues los recién casados no tuvieron descendencia.

Las primeras noticias de José Álvarez como maestro albañil las proporciona su carta de examen, fechada en Sevilla el 24 de marzo de 1763, obtenida tras superar los ejercicios propuestos por los alcaldes alarifes Mateo Rodríguez y Francisco de Lepe y el examinador Francisco Escacena "el menor", trazando y modelando "todo lo que le fue preguntado y dio buena cuenta y razones de todo ello". En ella declara ser natural de la villa de Huelva e hijo legítimo de Juan Álvarez y Paula de Mesa, siendo descrito como "alto de Cuerpo, moreno pelo castaño ojos pardos zerrado de barba, con una zicatris en ella y de edad de treinta y dos años", de lo que se infirió su nacimiento hacia 1731. Álvarez también declaró que "de mas de veinte años a esta parte usa el referido Arte por haverlo aprendido con Joseph Alvarez maestro de el en la citada Villa", lo cual implicaría que llevaba trabajando desde los diez años. Siendo que realmente lo vendría haciendo desde los dieciocho o diecinueve, puesto que su nacimiento se había producido ocho años antes, como se ha visto ${ }^{12}$.

Su carta de examen se acompaña de las certificaciones de su primo, José Clemente Álvarez, maestro albañil en Huelva, y de los notarios apostólicos Lorenzo Rodríguez Álvarez y Francisco de Paula Espinosa. José Clemente declara que José Álvarez es "natural de la expresada villa y Residente en la ciudad de Sevilla, como es notorio y me consta", confirmando que "de mas tiempo de veinte años a esta parte aprendio con migo el Oficio, estando mas de sinco años en mi compañía ejerciendolo y aprendiendo dicho Oficio, y que es hijo de tal Oficio, atento a que Nuestro Abuelo Paterno fue tanvien Mro. Alarife en dicha villa, y lo mismo Nuestros Padres", declaraciones ratificadas por los referidos notarios apostólicos.

La consideración hacia el maestro iba a ascender rápidamente, produciéndose el 21 de octubre de 1765 su nombramiento como maestro mayor de casas

11 Desposorio de José Álvarez con $\mathrm{M}^{\mathrm{a}}$ Vicenta Sanguino. Iglesia del Salvador. Sevilla, 8.sep.1750. AGAS, Parroq. del Salvador, Libro 13 de desposorios, Fol. 54v. Inédito:

"En ocho de Sepe de mil Setectos y Cinquenta años yo D. Jph Suarez Presbo de esta Ciudad de Sevilla y Vec de la Parrog del $S^{r} S^{n}$ Andres de dicha Ciudad, En virtud de Mandam ${ }^{\text {to }}$ de el $S^{r} J u e z$ de la Yga aviendo precedido todo lo dispuesto por derecho y no resultado Canonico impedimento, y aviendo Confessado para Cassarse, con permisso de el infrascripto Cura de esta Colegial de Sevilla Desposse y Casse por palabras de presente que hicieron Verdadero Matrimonio a Jph Alvarez natural de la $V^{a}$ de Guelva hijo de Juan Alvarez y de Paula de Messa, Juntamente Con Maria Vicenta Sanguino natural de esta Ciudad hija de Francisco Sanguino y de Maria Bogarin Siendo testigos D. Fernando Diaz Coronado Cura de dicha Collegial D. Francisco Sanguino y D. Jph Ramirez, todos Vec ${ }^{o s}$ de dicha Collegial Y lo firme Con dicho Cura".

12 Su carta de examen se acompaña de las certificaciones de su primo, José Clemente Álvarez, maestro albañil en Huelva, y de los notarios apostólicos Lorenzo Rodríguez Álvarez y Francisco de Paula Espinosa. José Clemente declara que José Álvarez es "natural de la expresada villa y Residente en la ciudad de Sevilla, como es notorio y me consta", confirmando que "de mas tiempo de veinte años a esta parte aprendio conmigo el Oficio, estando mas de sinco años en mi compañía ejerciendolo y aprendiendo dicho Oficio, y que es hijo de tal Oficio, atento a que Nuestro Abuelo Paterno fue tanvien Mro. Alarife en dicha villa, y lo mismo Nuestros Padres", declaraciones confirmadas por los referidos notarios apostólicos. AHMS, Sec. XVI, Antiguos 1663, Doc. 62, Caja 523 (HH/2517). 
del Cabildo eclesiástico en sustitución del recientemente fallecido Tomás José Zambrano, cargo por el que cobraría 400 ducados (4.400 reales) al año ${ }^{13}$. Al servicio de dicha institución, Álvarez llevaría a cabo numerosos reconocimientos, aprecios y valoraciones de obras en propiedades (solares, almacenes, casas y haciendas), sobre todo pertenecientes a las fábricas parroquiales ${ }^{14}$.

José Álvarez resultó elegido examinador del gremio en 1766 y 1768 y alcalde alarife en $1767^{15}$, ejerciendo oficiosamente la maestría mayor del Arzobispado de Sevilla al menos desde este último año, en que reconoce la ruinosa parroquial de Algámitas, prescribiendo las reconstrucciones que se necesitaba realizar en ella ${ }^{16}$.

El 30 de enero de 1768 da las condiciones para la reparación de la sacristía de la iglesia de Cañete la Real, reconociendo ese mismo año las obras que necesitaba la iglesia parroquial de Escacena, que valora en 174.536 reales. Dichas obras barroquizarían en gran medida la apariencia del templo, consistiendo en su ampliación, reparación de cubiertas y ejecución del coro ${ }^{17}$. Por aquellos años, al menos desde 1753, el maestro estaba empadronado con su esposa en la collación de San Andrés, residiendo en una casa propiedad de la fábrica de la Catedral sita en la "Callejuela de Passion, hazera de mano izquierda hazia las Monjas" (actual Vargas Campos) ${ }^{18}$.

El 22 de octubre de 1770 se aprobaron sus condiciones para proseguir con las obras de la parroquial de Trigueros. Antes, el 3 de septiembre, también ha-

13 Antonio SANCHO CORBACHO, Op. cit., p. 250. Tomás José Zambrano había sido enterrado en la parroquia de San Lorenzo el 5.Oct.1765 (APSL, Libro 15 de entierros, Fol. 269v).

14 Francisco OLLERO LOBATO: "Noticias de Arquitectura (1761-1780)", Fuentes para la historia del arte andaluz XIV (Dir. Jesús M. PALOMERO PÁRAMO). Sevilla, 1994, p. 40-45 y Francisco Sabas ROS GONZÁLEZ: "Noticias de Escultura (1781-1800)", Fuentes para la historia del arte andaluz XIX. Sevilla, 1999, p. 310, 755, 756 y 790.

15 Francisco OLLERO LOBATO, Op. cit., p. 510.

16 El procurador de fábricas solicitó el 7.Dic.1767 que, puesto que no podía acudir a Algámitas el maestro mayor Pedro de Silva, se ordenase "que Joseph Albarez Maestro mayor de obras de los Señores Dean y Cavildo desta $S^{\text {ta }}$. Yglesia pase a ebacuar dicha visita", presentando éste su informe el 6.Ene.1768. Al final de las obras de reconstrucción, Antonio de Figueroa ponderará el proyecto de José Álvarez: "entró a lo Ynterior de esta $Y g^{a}$. y de prompto no conocio si era aquella su situacion pues como estava hecho a ver nada mas que quatro Paredes y una Armadura que se asimilava a una Atarazana o bodega, Se quedó titubeando si era aquella la Yga. en que diversas ocaciones havia entrado...()...pues es cierto que de las buenas ocurrencias que a qualesquiera Artifice, se le pudiera venir a la Ymaginacion ha sido una la que al Maestro Joseph Alvarez se le previno para el proyecto de Aquella Obra; De lo qual se le deverán dar las gracias lo primero porque como dize, se halla hecha $Y g^{a}$. Lo segundo, porque sin perdida de sitio, con las Medias muestras y formeros que se han agregado a las dos Gualderas se le han dado mucha mas Valentia y Robustez a sus Paredes, lo tercero, porque con esta buena disposicion se aprovecharon todas las Maderas, Lo quarto, porque se ha podido Fortalecer la Armadura...()...con que por fin, por qualesquiera parte que se mire, fue un bello Pensamiento, assi por el mucho Lucimiento, Como por el ahorro que ha avido de lo que se hubiera gastado en el principal y partes de las Nuevas Maderas...()...Por lo que Vuelbe a repetir que es digno el Maestro Alvarez que se le den las gracias de esta tan buena Operacion". Informe de cumplido de Antonio de Figueroa, 16.Abr.1779. AGAS, Justicia, Pleitos ordinarios, Leg. 11314, Fol. 240r-241v.

17 AHPS, FPN, Of. 19, Libro de 1768, Fol. 150r-151v (Pub. en Francisco OLLERO LOBATO, Op. cit., p. 40, 42 y 510).

18 AHPS, FPN, Of. 19, Libro de 1765, Fol. 509r. APSAS: Padrones parroquiales de San Andrés 1753-1770. 
bía sido aprobado por el Cabildo catedralicio su informe para la realización del nuevo granero o casa cilla, dirigiendo las obras entre el 23 de octubre de aquel año y el 23 de octubre de $1772^{19}$. Y mientras ejecutaba la de Sevilla, en octubre de 1771 daba el maestro las trazas para la construcción de la cilla de Marchena. José Álvarez, su mujer y el ama Josefa Basosaba ya aparecen empadronados a mediados del año siguiente en la calle de la Muela (actual O’Donnell), donde residirá el alarife hasta el final de sus días.

El 10 de julio de 1772, el Cabildo aprobó la resolución de la Diputación de Negocios en orden a reparar la iglesia parroquial de Chucena "en la disposicion en que hoy está", pero haciendo presente la visita hecha por el maestro José Álvarez, que había delineado dos planos, "el uno con arreglo a el estado actual en que se halla dicha Yga y el otro en que demuestra como quedaria si se hiciese nuevo el cuerpo de Ygal". La Diputación resolvió aprobar la reparación de lo dañado, valorada en 17.900 reales de vellón, en lugar de derribar el cuerpo de iglesia y labrarlo de nuevo "a correspondecia de la Capilla mayor", por ser un gasto puramente voluntario que excedería en 60.000 reales a la simple reparación y porque la extensión que se conseguiría no causaría ningún desahogo al vecindario $^{20}$. Posteriormente, por auto capitular de 23 de junio de 1773, se acometió a la Diputación de Negocios "el nuevo Plan y parecer formado por el Maestro mayor Jph Alvarez de la obra de la Yga de Chuzena", resolviendo aquélla derribar el cuerpo de iglesia, al haberse comprobado la debilidad de sus cimientos, y proceder a la reedificación del mismo. A estas obras, valoradas en 67.900 reales de vellón, había que añadir una ampliación de dos varas, "por el aumento del vecindario, de que se informo mui prolixamente"21.

El 14 de julio de ese año presenta el maestro una propuesta de ampliación de la iglesia de Algodonales por la cabecera y los pies, que es muy criticada por el procurador de fábricas ${ }^{22}$. En 1775 practica visita a la iglesia de San Gil de

19 Juan Carlos HERNÁNDEZ NÚÑEZ: "El granero del cabildo hispalense: Historia y edificación”, Archivo Hispalense, nº 217, Sevilla, 1988, p. 223-235. Fue sede del Museo de Arte Contemporáneo de Sevilla, albergando en la actualidad dependencias del Archivo General de Indias.

20 ACS, FC, Secretaría, Diputación de Negocios, Libro 07380, Fol. 125r-126r.

21 Ibídem, Fol. 149r-v.

22 Se había establecido una polémica entre Pedro de Silva y Antonio de Figueroa, apoyando aquél la ampliación propuesta por Álvarez y rechazando el proyecto de nueva planta de Figueroa. Sin embargo, el informe de 23.Jul.1774 del procurador de fábricas contra Silva y Álvarez es demoledor: "...ha presentado el plano del folio 74 que aunque no está firmado de Maestro alouno, parece segun se dice que lo hizo Joseph Alvarez, y sea el que fuere su autor, basta verlo para conocer que solo por contemplacion se pudo concebir la idea de una Yglesia de 44 varas de largo y 16 de ancho contra todas las reglas de Architectura, y que acaso no se dará exemplar en todo el Arzobispado; Y mas extraño es que Pedro de Silva se conformase con semejante Proyecto...()...y no puede dexar de extrañarse que Pedro de Silba se incluia tambien en esto, quando lo que debiera hacer en el caso de que por VS. se le mandase dar dictamen era averiguar el vecindario y hacer las demas regulaciones que hizo Antonio de Figueroa, y deben servir de presupuesto a qualesquiera que quiera darlo con fundamento solido, en vista de lo qual y demas que contienen los dictamenes voluntarios de Silva y Alvarez, no es el proyecto de Figueroa el que merece el nombre de monstruoso, ni sus ideas el de extravagantes...". ADJF, FH, 1171, 822, Ordinarios, Caja 2, Fol. 85r-94r. 
Écija, demarcando el emplazamiento de la nueva torre y dando parecer sobre su construcción, cuyas obras valora en 80.000 reales ${ }^{23}$. Ese mismo año traza los planos de la iglesia de San Pedro de Jerez de la Frontera ${ }^{24}$ y, conjuntamente con Antonio de Figueroa, José Álvarez realiza obras de reforma en el Salón del Trono del Palacio Arzobispal de Sevilla ${ }^{25}$.

\section{JOSÉ ÁLVAREZ COMIENZA A RECIBIR IMPORTANTES ENCARGOS DEL ARZOBISPADO PARA CONSTRUIR IGLESIAS DE NUEVA PLANTA}

El año 1776 será clave en la carrera profesional de José Álvarez, ya que proyectará para la diócesis dos monumentales templos, el de Moguer y el de Santa Cruz de Écija ${ }^{26}$.

La primitiva iglesia mudéjar de Nuestra Señora de la Granada de la ciudad de Moguer se había visto dañada a consecuencia del Terremoto de Lisboa de 1755, según informaba el maestro mayor Pedro de San Martín el 26 de abril del año siguiente, dando condiciones y aprecio para las reparaciones de la torre y construcción de nueva sacristía y comunes, trabajos que estimó en 22.500 reales de vellón ${ }^{27}$. Los subsiguientes reconocimientos del estado de las obras, comenzadas el 10 de octubre de 1756, los realizaría Pedro de Silva, quien inspeccionó la reforma agiraldada de la originaria torre del siglo XIII, ejecutada entre junio de 1758 y marzo de 1760 por los alarifes moguereños Antonio Guerrero y Manuel Ruiz y por Lucas Cintora, valorando lo ejecutado en no "menos de tres mil pesos" 28 . Este elemento sería el único que iba a conservarse de la antigua fábrica.

Decidida la ampliación del templo por la escasa capacidad de la vieja iglesia mudéjar, los autos para acometer dichas obras principiaron el 8 de junio de 1775, encomendándose a José Álvarez el 28 de julio el reconocimiento del edificio y su posible ampliación. El 8 de marzo de 1776, tras verificar la exigua cabida del templo, propone construir cuatro nuevas capillas, cubiertas con bóvedas vaídas, en los porches contiguos a las naves menores y nuevos panteones debajo de ellas, así como proyecta dos nuevas portadas laterales de ladrillo

23 ACS, FC, Contaduría, Leg. 06204, Fol. 70r-v. La torre de San Gil sería ejecutada por Antonio Caballero entre 1777 y 1782, debiéndose a Antonio de Figueroa las condiciones para la realización del campanario. Véase José Manuel HIGUERA MELÉNDEZ: “Las intervenciones en Écija del maestro mayor Antonio de Figueroa (1733-1793): una obligada puesta al día", Isidorianum, $\mathrm{n}^{\circ}$ 49, Sevilla, 2016, p. 107-158.

24 Antonio SANCHO CORBACHO. Op. cit., p. 251.

25 Teodoro FALCÓN MÁRQUEZ: "El Palacio Arzobispal de Sevilla ", Publicaciones Obra Social y Cultural Cajasur. Córdoba, 1997, pp. 117-122.

26 Ese año será también uno de los maestros requeridos por el Cabildo en relación con los nuevos síntomas de ruina que presentaba la iglesia del Sagrario, informando el 20.Feb y el 24.Abr.

27 ADH, Justicia, Moguer, $396^{1}$ A, Caja 358, Fol. 2r-5r.

28 Pedro de Silva informó de cumplido estas obras el 26.Jun.1760. Ibídem, Fol. 116r-117v. 


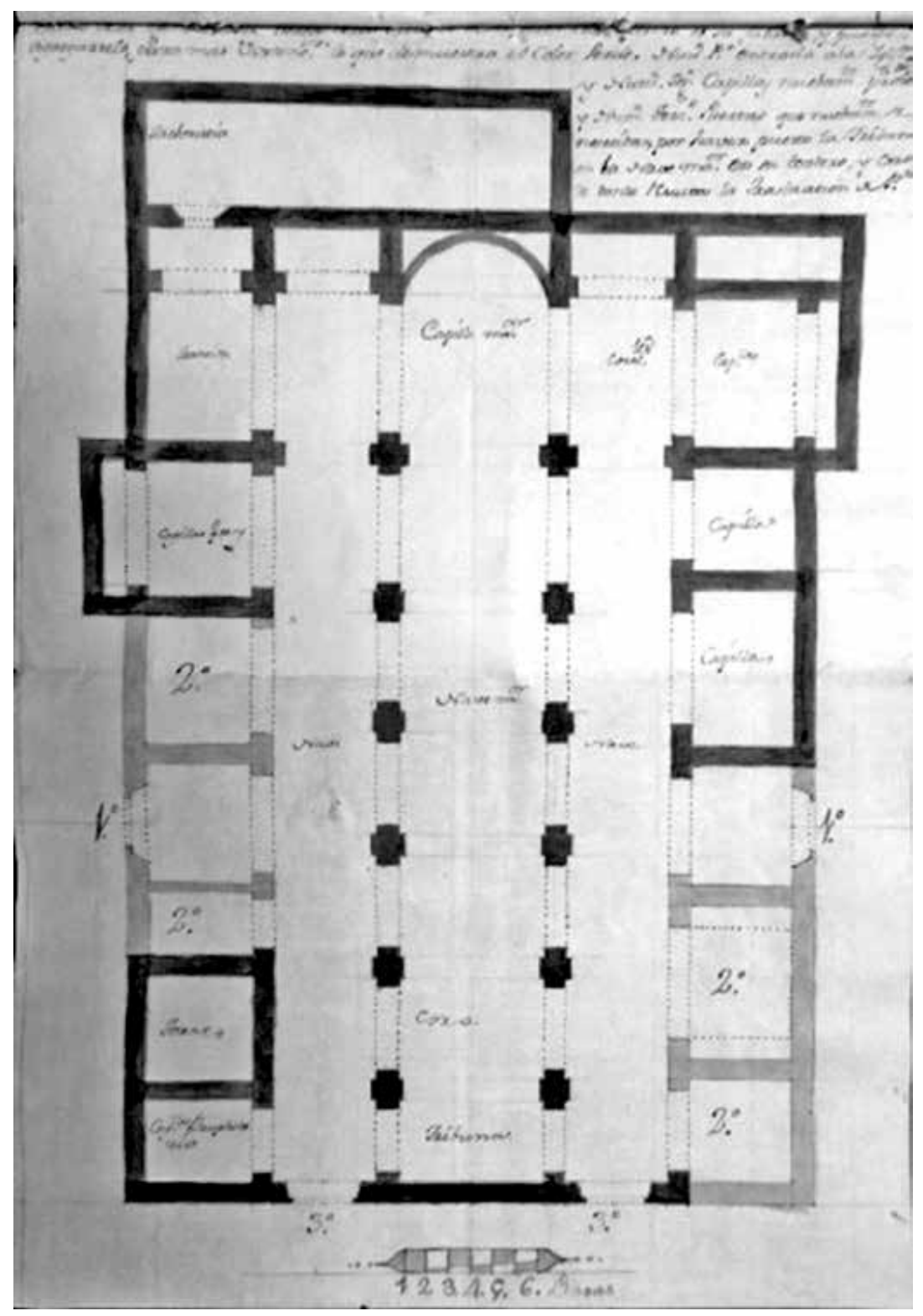

Figura 1. Planta de la propuesta de José Álvarez de 8 de marzo de 1776 para ampliar la primitiva iglesia gótico-mudéjar de Moguer (trazo oscuro), mediante la adición de cuatro capillas en los porches laterales (trazo claro). Finalmente el templo sería derribado, construyéndose uno nuevo en el que se integraría la preexistente agiraldada torre. Archivo Diocesano de Huelva, Justicia, Moguer, Caja 344.

cortado y orden dórico, presentando plano de planta de su propuesta.Valora la ampliación en 50.000 reales de vellón ${ }^{29}$, siendo otorgada la licencia diocesana el 9 de mayo de 1776.

Sin embargo, el 6 de septiembre, una vez comenzadas las obras, Álvarez informa de la debilidad de cimientos, muros y arcos de la antigua iglesia, proponiendo entonces construir un nuevo templo en el que se podrían integrar la torre y parte de los panteones y sacristía existentes. El maestro presenta planos

29 ADH, Justicia, Moguer, Caja 344, Fol. 17r-19r. 
de planta y sección, que no se conservan, valorando las obras en más de 700.000 reales de vellón, "sin incluir el costo del sitio que ocupan las casas que ha de comprar la Fabrica"30, siendo preciso tomar un pedazo de calle y dos casas. Las obras comenzarían en marzo de 1777, bendiciéndose el nuevo edificio el 19 de agosto de $1786^{31}$.

José Álvarez construye en Moguer un templo de planta rectangular con cinco naves ${ }^{32}$ separadas por pilares de planta cuadrada con pilastras adosadas y esquinas redondeadas. Crucero y cabecero plano, constando el cuerpo de iglesia de cuatro tramos. La sacristía y demás servidumbres se sitúan tras la capilla mayor, ubicándose la capilla bautismal junto a la preexistente torre, no disponiéndose tribuna a los pies de la iglesia. La nave central se cubre con bóveda de cañón de amplios lunetos que la convierten en bóvedas por arista, cerrando mediante bóvedas vaídas las naves colaterales y por arista las extremas. Por su parte, los brazos del crucero y el cabecero se cubren con bóvedas de cañón con lunetos, cobijando el espacio central una media naranja sobre tambor con cuatro ventanas y ocho óculos, elementos que se manifiestan al exterior en planta hexadecagonal, trasdosándose la cúpula mediante dieciséis gallones curvos sin tejas. El orden interior es el corintio, por tratarse de una iglesia dedicada a Nuestra Señora ${ }^{33}$, corriendo todo el entablamento sobre los arcos intercolumnios. Tres puertas decoradas con portadas de ladrillo dan entrada al templo, siendo la principal la ubicada a los pies de la iglesia, en la cual los dos pares de columnas que flanquean el vano de medio punto sostienen un entablamento con triglifos y metopas que se curva en su parte central ${ }^{34}$. En un segundo cuerpo, cuatro columnas de orden jónico sobre las que apoya un frontón curvo encuadran una hornacina, coronando un ático con vano mixtilíneo. La portada se remata con el óculo de la nave central y el hastial curvo, quedando enmarcado todo el conjunto mediante dos órdenes de pilastras cajeadas, el inferior dórico y jónico el superior. Las cubiertas de las naves son de teja, con la tradicional jerarquización volumétrica exterior para formar la cruz, abriéndose ventanas en los muros de la emergente nave central y también en las extremas, debido a la excepcional latitud del templo. La nave mayor, que

$30 \quad$ Ibídem, Fol. 32r-42r.

31 "La edificación de la parroquial de Moguer en 1776 y nueva decoración en 1896", conferencia pronunciada en Moguer el 10.Sep.2015 por D. Juan Manuel Moreno Orta, historiador y Conservador del monasterio de Santa Clara de Moguer, a quien agradezco la amabilidad de enviarme su transcripción.

32 El 17.Oct.1783, Álvarez proyectará la adición de una nueva nave a las cuatro con que contaba la iglesia de San Eutropio de Paradas, si bien las obras se ejecutarían finalmente según las posteriores trazas de Fernando Rosales. AGAS, Justicia, Pleitos ordinarios, Leg. 10312, Fol. 3r-6r.

33 "... y por razon de ser el templo dedicado a $N^{a}$. Me. y Sra. S" Maria, la orden que se seguira en todo su interior sera la Chorintia" (Informe de Pedro de Silva de 15.Oct.1757, dando trazas y condiciones para la nueva iglesia de Santa María de Écija. AGAS, Justicia, Pleitos ordinarios, Leg. 10691, Fol. 4r-7r).

34 Elemento tomado de las portadas de Ambrosio y Antonio de Figueroa. 
teja la mayor parte de su longitud a dos vertientes, dispone un faldón inclinado hacia el hastial curvo de los pies, mientras cada par de naves laterales se cubren a un agua, haciéndolo a tres los brazos del crucero, dotados igualmente de ventanas, y el cabecero. José Álvarez dispone que los aleros de los tejados queden ocultos por pretiles de fábrica, evacuando las aguas llovedizas a través de huecos abiertos en la base de aquéllos. El maestro ubica una buhardilla de ventilación sobre cada uno de los dos faldones de la nave central y sobre los brazos del crucero y el cabecero. Finalmente, por lo que a las fachadas de la iglesia se refiere, éstas se articulan mediante pilastras dóricas sobre las cuales corre un entablamento con unos modillones a modo de triglifos que conforma también la cornisa de las naves laterales, recuperando esquemas herrerianos de austero clasicismo ${ }^{35}$.

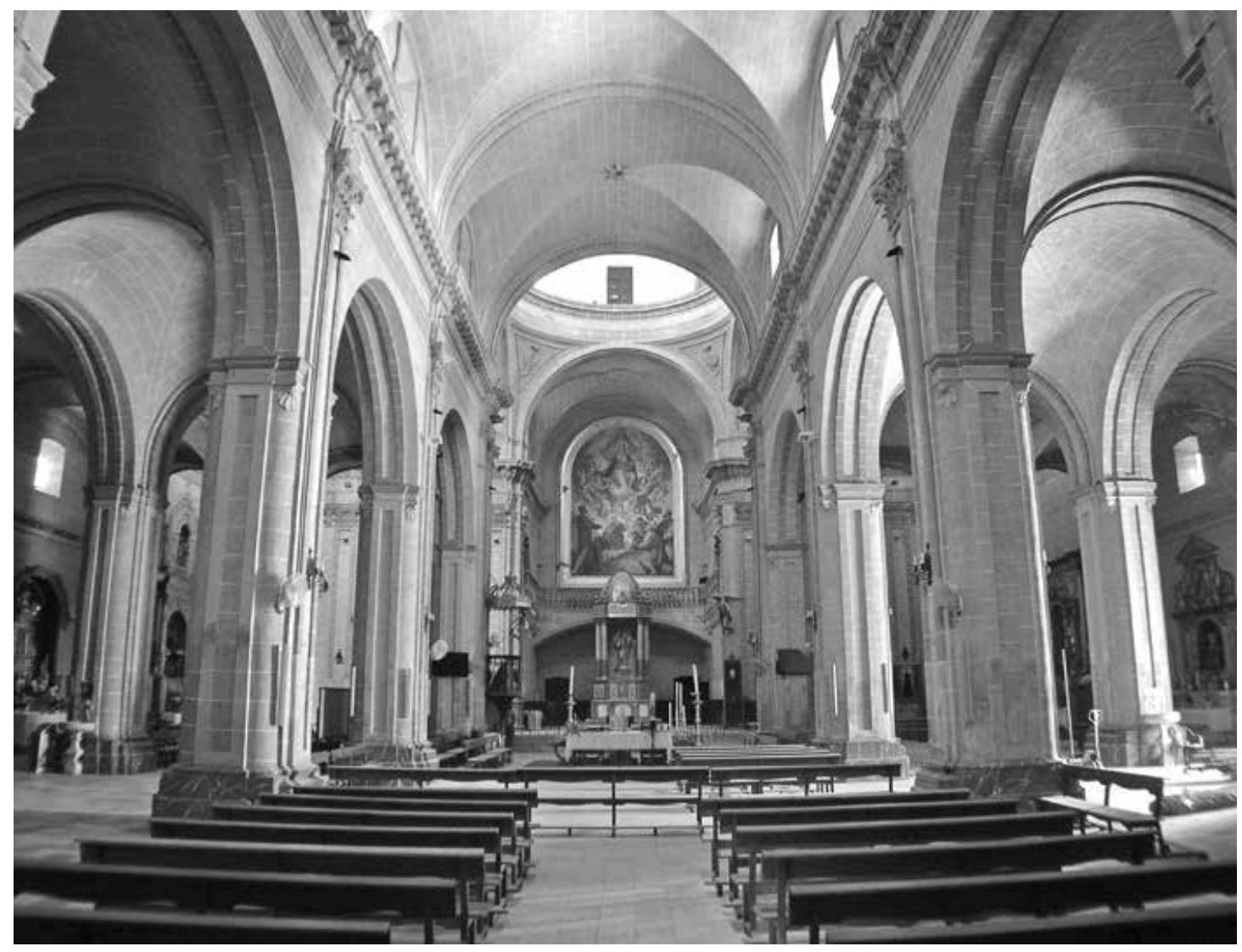

Figura 2. Iglesia de Ntra. Sra. de la Granada de Moguer, monumental templo de cinco naves proyectado por José Álvarez en septiembre de 1776, cuya construcción abarcó de 1777 a 1786. Al tratarse de un templo dedicado a Nuestra Señora, el maestro mayor dispuso el orden corintio en su interior. Fotografía del autor.

35 La formalización exterior de la iglesia de Moguer, mediante un orden dórico con peculiares triglifos y los pretiles de remate en los faldones inclinados, se inspira en las fachadas de la parroquial de Las Cabezas de San Juan, aunque es de apariencia mucho más clasicista que aquélla. 
A finales de 1775, tras los requerimientos iniciales de la fábrica de la iglesia mayor de Santa Cruz de Écija, es enviado allí José Álvarez, quien informa el 24 de noviembre del mal estado de las cubiertas, así como ser preciso agrandar las tres puertas para poder dar salida a los pasos de Semana Santa y ejecutar nuevos enterramientos $^{36}$. Dichas obras son autorizadas, comenzando los derribos proyectados el 2 de enero de 1776. Tras su visita de marzo de ese año, Álvarez prescribe demoler también las gualderas por no ser de buena fábrica ${ }^{37}$, ordenándosele entonces que "reconosca el mejor modo de dar mas extension a la citada Yglesia". Habiendo calicatado la fábrica antigua, resulta estar "todo executado en diferentes tiempos por que asi como la Yglesia es detantos agregados por razon de irla esplayando assi estan los cimientos executados a retazos, y por la misma causa no hay seguridad y lo mismo en los Muros que en los Posteles de la Nave mayor", por lo que "tiene por justo y preziso el que se construya toda la Yglesia como lo lleva dicho de nueva Fabrica". Añadiendo que "para mas claridad de lo que lleva explicado ha formado Plan orizontal assi de la Yglesia que es oy y demas Ofizinas, y del Sitio que se puede tomar asi de Calle como de Casas; y asimismo Plan para la Yglesia nueva en los mismos terminos que lleva expuestos"38. La Diputación de Negocios aprobó la construcción de una nueva iglesia y "le mando a el Maestro maior que trase alsados y Haga condiciones, y relacionadas, $Y$ el costto que regule para la Obra de dicha Yg ${ }^{a}$. con arreglo a dicha exttencyon"39.

José Álvarez propone en Santa Cruz una iglesia de planta rectangular de sesenta varas de longitud y cuarenta de latitud "de fuera a fuera", con un zócalo exterior perimetral de piedra de Estepa de una vara de alto. El templo se distribuye en tres naves, crucero y cabecero, rematando la profunda capilla mayor una exedra semicircular, en tanto se disponen baterías de amplias capillas hornacinas en los laterales del templo a correspondencia con cada uno de sus cuerpos. La sacristía y demás servidumbres se ubican detrás de la capilla mayor. La nave principal, dividida en tres tramos y de diez varas de ancho, quedaría cubierta con bóveda de cañón con lunetos, disponiéndose bóvedas por arista en las naves laterales, de siete varas de latitud, vaídas en el crucero y la capilla mayor y por arista en las capillas colaterales a ésta. El espacio central del crucero se cubre con una media naranja sobre un cuerpo apilastrado en el que se abren claraboyas, quedando rematado el conjunto con una linterna. En los formeros de las bóvedas que cubren las tres naves, el crucero y las colaterales, se dejan ventanas, disponiéndose en la fachada principal dos puertas a los pies de las naves laterales, en tanto se cierra el testero central para colocar el coro ${ }^{40}$.

36 AGAS, Justicia, Pleitos ordinarios, Leg. 10319, Fol. 56r-57r.

37 Ibídem, Fol. 64r-66v. Informe de 22.Mar.1776.

38 Ibídem, Fol. 78r-82v.

39 Ibídem, Fol. 148r-155v. Es decir, las obras para las que se otorgó licencia a finales de 1775, comenzadas el 2.Ene.1776, no eran para construir nueva iglesia, sino para reformar la vieja, ya que hasta marzo de 1776 no fue presentado y autorizado el proyecto de nueva planta de José Álvarez.

40 Disposición de fachada similar a la prescrita por Antonio de Figueroa en octubre de ese año de 1776 para la ampliación por los pies de la parroquial de Bollullos del Condado. 
Álvarez también prescribe que sobre el cañón de la nave mayor se dispondrá una armadura de madera de pino flandes, en tanto que sobre las bóvedas de arista de las naves laterales se formarán empalomados de citaras de ladrillo para formar as pendientes de los tejados, haciendo desaguar éstos sobre las albardillas de las gualderas en lugar de hacerlo directamente al vacío. El maestro presupuesta las obras en 783.356 reales, incluyendo las bóvedas para enterramientos.

Todas las cubiertas serían de teja, con la tradicional jerarquización volumétrica exterior para formar la cruz, abriéndose ventanas en los muros de la prominente nave central, tejada a dos vertientes y posiblemente con faldón inclinado hacia la fachada de los pies. Las elevadas naves menores, con una altura de casi catorce metros, también disponen de ventanas en los formeros de sus bóvedas. cubriéndose a un agua. Finalmente, los brazos del crucero, donde también se abren ventanas, y el cabecero lo hacen a tres.

La monumentalidad del proyecto de José Álvarez es bien patente, reflejándose tanto en la amplitud que proporciona a las naves como en la propia planta, inspirada en la sevillana colegial del Salvador, cuyo rasgo más característico es la presencia de capillas hornacinas en los muros laterales. Dichas capillas perimetrales, que en el templo sevillano sustentan la tribuna superior, pierden aquí esta característica funcional, prevaleciendo la misión estructural de arriostramiento de sus elevados muros laterales. Al tiempo que se dota al templo de un aspecto más propio de una colegiata que de una iglesia parroquial, que era el objetivo perseguido por la fábrica de Santa Cruz en su particular pugna con la de Santa María.

Otros elementos reseñables de la planta trazada por Álvarez son los singulares soportes cruciformes mixtilíneos con pilastras adosadas de sinuoso perfil, atribuidos por Sancho Corbacho erróneamente a la intervención de Antonio de Figueroa, pues éste visitará las obras por primera vez para reconocerlas el 23 de julio de $1785^{41}$, cuando ya estaban construidos todos los pilares y arcos de las naves menores ${ }^{42}$. Lo cierto es que la traza y alzados de la iglesia de Santa Cruz se deben a José Álvarez, como queda documentado, proyectando Figueroa las bóvedas de enterramientos, pero en la tardía fecha de 15 de septiembre de $1788^{43}$.

Las fachadas diseñadas por el maestro onubense también se inspiran en la colegial del Salvador, articulándose mediante la continua modulación establecida por pilastras pareadas de orden dórico que aportan sobriedad clasicista al conjunto. De haberse rematado, la fachada principal con el preeminente volumen de la nave mayor, probablemente flanqueado por volutas, y sus dos grandes portadas sería sin duda una de las mejores de la archidiócesis.

41 AGAS, Justicia, Pleitos ordinarios, Leg. 10319, Fol. 328r-333v. El 29.Jul.1785, Antonio de Figueroa presta su declaración relativa a la visita que hizo a las obras el 23 de dicho mes.

42 La similitud de los soportes de Santa Cruz con los pilares torales de Peñaflor, junto con otras deducciones, llevaron al historiador a atribuir erróneamente las trazas y la ejecución de la iglesia de dicha villa a Antonio de Figueroa (Antonio SANCHO CORBACHO, Op. cit., p. 219-222).

43 AGAS, Justicia, Pleitos ordinarios, Leg. 10319, Fol. 364r-365r. 


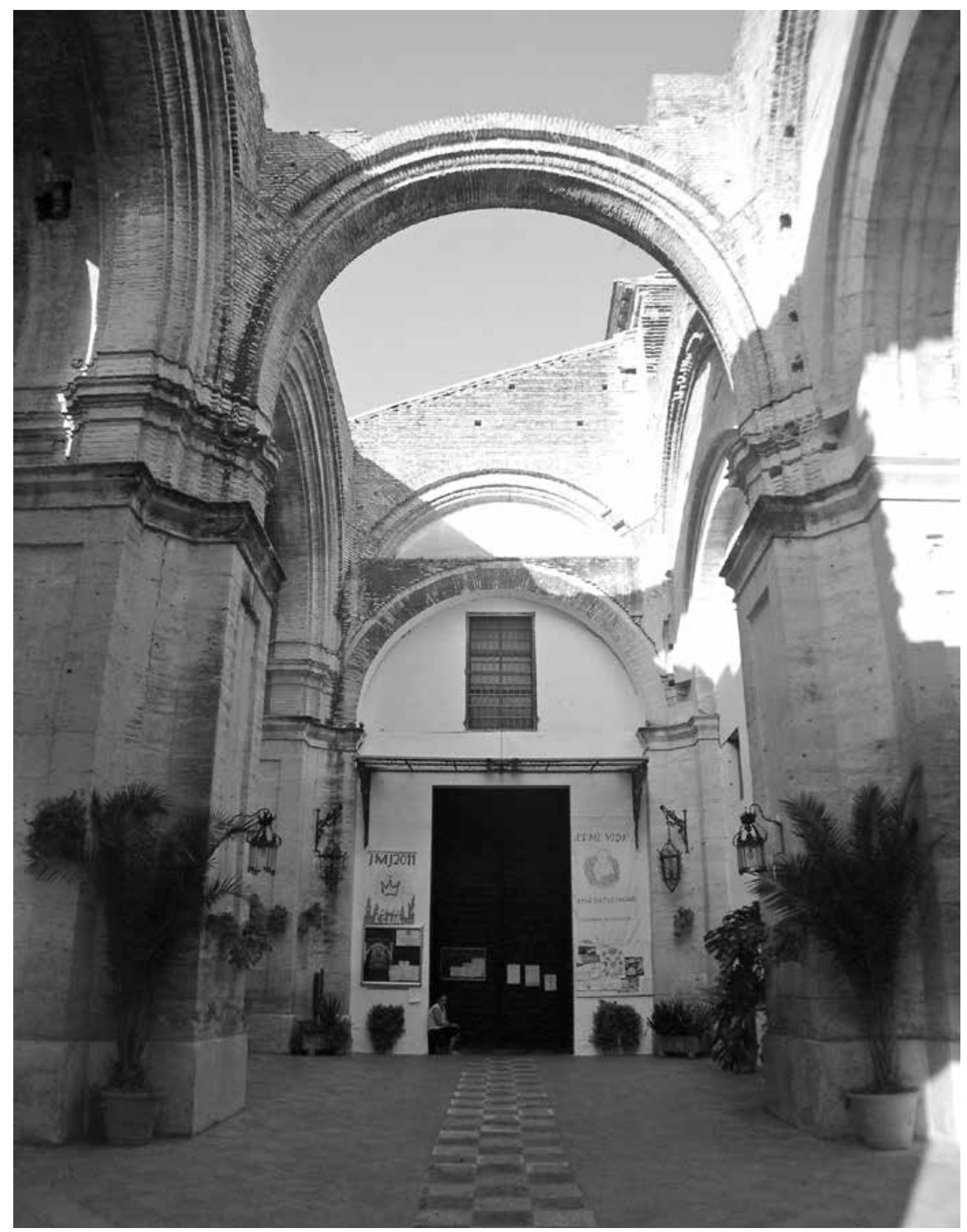

Figura 3. Nave en alberca de la iglesia de Santa Cruz de Écija, que le sirve en la actualidad de atrio de acceso. Se aprecia la estructura original latericia de pilares y arcos, parcialmente recubierta por la fábrica de piedra que dispuso, a partir de 1791, el arquitecto Ignacio Tomás. Proyectado con gran monumentalidad por José Álvarez en marzo de 1776, problemas estructurales y económicos impidieron finalmente la terminación del templo. Fotografía del autor.

Sin embargo, al contrario que la de Santa María, la fábrica de Santa Cruz no vería recompensados sus esfuerzos con la finalización del grandioso templo, que quedaría a medio construir debido a problemas estructurales que redundaron en un incremento del presupuesto al que no pudo hacer frente la diócesis. 
Así, con la terminación de menos de la mitad del cuerpo de iglesia y sensiblemente desfigurado el interior por la intervención del arquitecto académico Ignacio Tomás, se abrió al culto el templo el 21 de diciembre de $1836^{44}$.

Como comentario final, recientes investigaciones han permitido establecer que las obras del nuevo templo de Peñaflor se vieron influidas decisivamente por las de Santa Cruz, comenzadas dos años antes que aquéllas ${ }^{45}$.

El 12 de julio de 1776, José Álvarez proyecta obras de reparación y ampliación de servidumbres en la sevillana iglesia parroquial de la Magdalena ${ }^{46}$, ejecutando diversas reformas ese mismo año en la antigua iglesia parroquial de San Bernardo ${ }^{47}$.

El 26 de octubre de 1776 daba el maestro plano y condiciones para reedificar de nueva planta la iglesia de Algodonales en el mismo solar que ocupaba el antiguo templo mudéjar. Sitúa una puerta en la nave del evangelio dando a la plaza, dos a los pies y coro ocupando el centro del hastial. Sobre el coro, una tribuna a todo lo ancho de las tres naves, tal y como había proyectado Antonio de Figueroa unos días antes, el 12 de octubre, para la reforma de la iglesia de Bollullos del Condado. Álvarez amplía algunas varas la longitud y anchura proyectadas por Figueroa, siguiendo básicamente las condiciones dadas por éste en su proyecto de 26 de junio de 1773, adosando además la capilla bautismal en el lado del evangelio y la torre al lado de la epístola, ambas a los pies de la iglesia ${ }^{48}$. Por la Providencia de 9 de noviembre de 1776, "...se mando con efecto construir con arreglo a uno de los Planos formado y delineado por Josef Alvarez...". El 15 de abril de 1777, José Álvarez y Antonio de Figueroa propusieron que la nueva iglesia se hiciera, con algunas modificaciones en la extensión de las naves, conforme al plano de Álvarez de octubre de 1776, pero integrando en el rectángulo de la planta la capilla bautismal y la torre (que éste adosaba a los pies de la iglesia), y dejando en dicho hastial a la plaza una única portada en lugar de dos.Y asimismo conforme a las condiciones, distribución y volumetría de Figueroa, quien había propuesto girarla $90^{\circ}$ para que la fachada principal, situada a los pies de la iglesia, mirase a la plaza. Este sería el proyecto llevado a cabo, aunque finalmente no se realizaría la tribuna a todo lo ancho de las naves ${ }^{49}$.

44 Aunque tradicionalmente se viene atribuyendo un papel relevante a José Álvarez en la ejecución de la ecijana iglesia de Santa María, ha quedado documentado que apenas intervino en dichas obras. Véase José Manuel HIGUERA MELÉNDEZ, Op. cit.

45 José Manuel HIGUERA MELÉNDEZ: "La iglesia de San Pedro Apóstol de Peñaflor (Sevilla). Paisaje, arquitectura y construcción en el contexto clasicista de finales del siglo XVIII", tesis doctoral inédita, Sevilla, 2015.

46 AGAS, Justicia, Pleitos ordinarios, Leg. 12696.

47 Antonio SANCHO CORBACHO, Op, cit., p. 254.

48 ADJF, FH, 1171, 822, Ordinarios, Caja 2, Fol. 295r-306r.

49 El 15.Jul.1782, José Álvarez declaraba que "la Yglesia toda esta executada con arreglo a el Plano que dio el que declara, assi Capilla Mayor como Presviterio, cuerpo de Yglesia, media naranja y Cavesero, y Cañón de la Nave Mayor y menores cubiertas de bóvedas, todo está con arreglo a el Plano y Alzado del que declara; y por la parte exterior y tribunas con otro alzado que hizo Figueroa". Ibídem, s.f. 
El 19 de octubre de 1779, José Álvarez informa favorablemente los planos para la nueva iglesia parroquial de San Bartolomé de Sevilla presentados por José Echamorro, que valoró las obras en 400.000 reales $^{50}$.

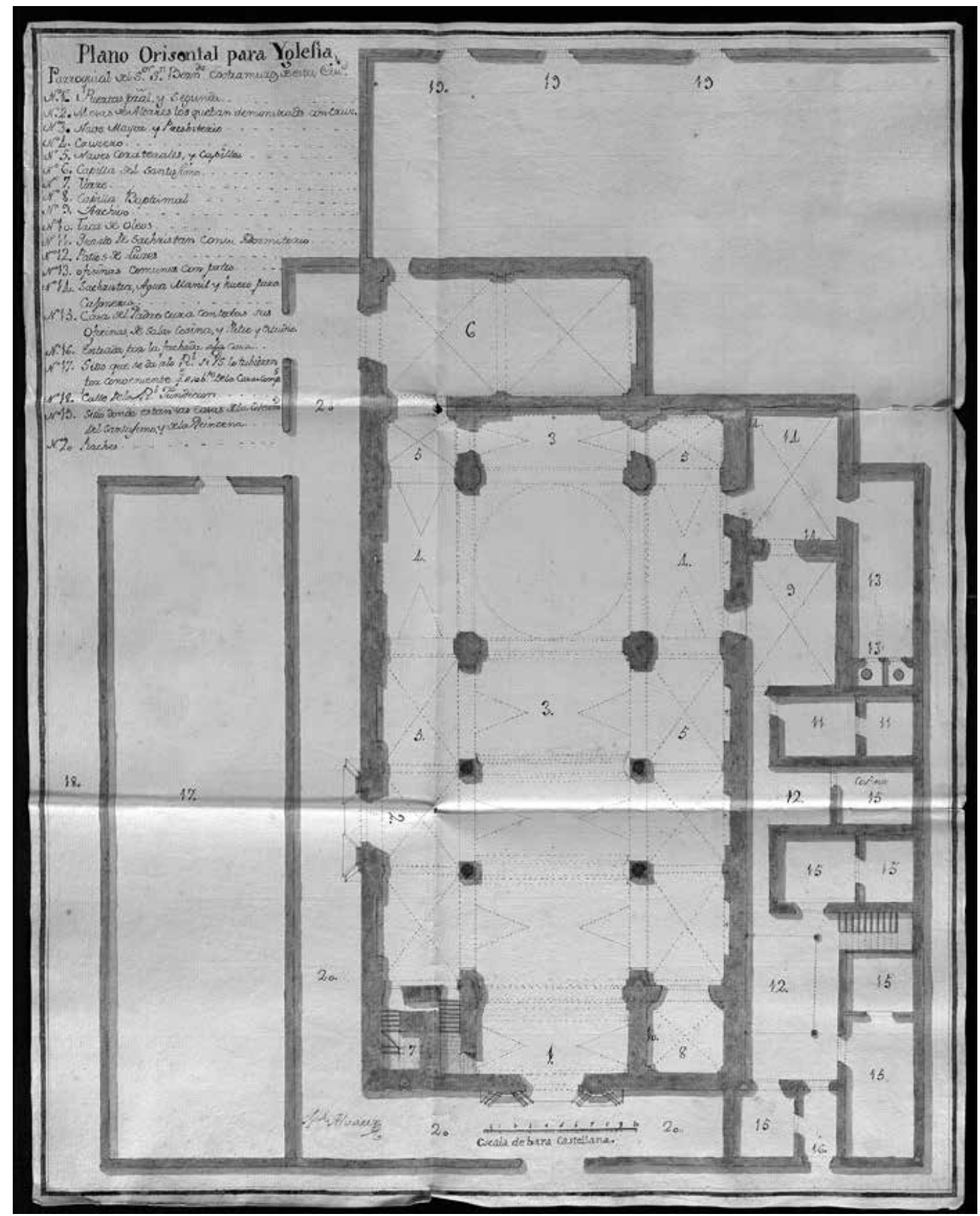

Figura 4. Plano de planta para la nueva iglesia de San Bernardo de Sevilla, presentado por José Álvarez ante el Cabildo el 10 de mayo de 1780. La propuesta fue aceptada, con la condición de sustituir las columnas proyectadas por el maestro por pilares de mampostería o ladrillo. Inédito. Archivo Catedral de Sevilla, Fondo Capitular, Materiales especiales, $n^{\circ} 619$.

50 ALa iglesia se ejecutaría finalmente según la traza y condiciones de Antonio de Figueroa. 
Otra iglesia hispalense que el Cabildo eclesiástico decidió reedificar sería la antigua iglesia de San Bernardo, encargándose el proyecto a José Álvarez, quien presentó planos de planta y sección longitudinal el 10 de mayo de $1780^{51}$. El maestro había trazado un edificio de cuarenta varas de longitud y veinte de latitud "sin incluir los muros ni grueso de postteles", con crucero, bóvedas subterráneas en la capilla mayor y soportes columnarios separando las naves, valorando su ejecución en 520.000 reales de vellón. La propuesta fue aceptada por el Cabildo dos días después, aunque "con la diferencia de haver de extenderse su longitud a 45 varas Castellanas, y las Bobedas para entierros a toda la longitud de la Nave pral y que los Arcos de esta se sostubiesen con postes de mamposteria o ladrillo, y no con columna"52.

El 23 de mayo presentó las condiciones Álvarez, proyectando entonces un templo de tres naves separadas por pilares de planta rectangular con pilastras adosadas, crucero y cabecero plano, constando el cuerpo de iglesia de tres tramos. La sacristía y demás servidumbres se sitúan detrás de la capilla mayor y de la capilla colateral de la epístola, ubicándose a los pies de la iglesia la capilla bautismal, la tribuna del órgano y la torre. La cubierta de la nave central es una bóveda de cañón con lunetos, cobijándose con bóvedas vaídas las laterales y la colateral de la epístola, en tanto la capilla sacramental, situada al lado del evangelio, cubre sus dos tramos mediante bóvedas semiesférica y vaída. Brazos del crucero y cabecero se guarecen con bóvedas de cañón con lunetos, cubriendo el espacio central una media naranja con linterna sobre tambor, en el que se abren cuatro ventanas, aunque inicialmente estaba prevista una simple bóveda vaída sin linterna. El tambor y la cúpula ejecutados se trasdosan al exterior en planta ochavada, tejándose ésta mediante los habituales ocho faldones contracurvados, con la novedad de emplear teja vidriada blanca y azul. Decorándose la linterna con ocho columnillas corintias sobre pedestales que enmarcan vanos de medio punto. El orden interior de la iglesia es el dórico, y al igual que en Moguer, se corre todo el entablamento, decorado esta vez con triglifos y metopas, sobre los arcos intercolumnios. Dos puertas decoradas con portadas de ladrillo dan acceso al templo, una en la nave del evangelio y otra en la fachada principal, en la cual dos semicolumnas flanquean el vano de medio punto, sosteniendo un frontón recto y partido sobre entablamento con triglifos y metopas, que enmarca el segundo cuerpo. En éste, dos columnillas de orden jónico y entablamento mixtilíneo, sobre las que apoya un frontón curvado, encuadran una hornacina de medio punto con la imagen del titular, rematando el conjunto las distintivas jarras de azucenas y una giralda delante del óculo central. Sobre la portada se dispone un friso decorativo y un cornisón que festonean la nave central de la iglesia y los brazos del crucero y cabecero, ubicándose una buhardilla para

$51 \quad$ ACS, FC, Materiales especiales, nº 618 y 619.

52 ACS, FC, Contaduría, Leg. 12316, Exp. 1. Se había afirmado que Álvarez también presentó una solución con pilares de ladrillo (Antonio SANCHO CORBACHO, Op. cit., p. 254-255). 
ventilación del faldón de la cubierta, quedando enmarcado lateralmente el conjunto mediante dos resaltes a modo de pilastras. La portada del evangelio es más sencilla, enmarcando dos pilastras con contrapilastras que sostienen un frontón recto y roto, un vano de medio punto. Todas las cubiertas son de teja, vidriada en caballetes y limatesas, con la habitual jerarquización volumétrica exterior para formar la cruz, abriéndose vanos de iluminación en los muros de la prominente nave central, tejada a tres vertientes al igual que los brazos del crucero y el cabecero, también dotados de ventanas. Como en Moguer, Álvarez dispone ventanas en la nave del evangelio, cubierta a un agua.

La cajeada caña de la torre, en la que se abren dos balcones y varios óculos, iguala la altura del caballete de la nave central, ubicándose encima el cuerpo de campanas de un vano por cara flanqueado por pilastras corintias pareadas ${ }^{53}$. El último cuerpo lo forma un rebanco ochavado curvado, sobre el que se dispone una original pieza prismática octogonal con hornacinas, rematado con cupulín. La iglesia se bendijo solemnemente el 19 de agosto de 1785.

Si los alzados exteriores de Moguer se articulan mediante pilastras dóricas y un entablamento con triglifos y metopas para dotarlas de un sobrio hálito clasicista, en San Bernardo vuelve José Álvarez a la estética formal barroca, mediante la aplicación de todo un repertorio de pinjantes, volutas, remates de azulejo y ladrillo, coloridos frisos geométricos, ausencia de triglifos y metopas en entablamentos y la recuperación del avitolado de paramentos. Por contra, el interior es netamente clasicista, recorriendo un ancho friso de triglifos y metopas la nave central, el crucero y el cabecero. Parece como si el maestro reconociera la supremacía del carácter barroco de la ciudad, no atreviéndose a exteriorizar el espíritu academicista que indudablemente subyacía en su quehacer profesional ${ }^{54}$.

El 28 de marzo de 1781, José Álvarez y Antonio de Figueroa plasmaron conjuntamente las trazas y condiciones para la ampliación de la antigua iglesia mudéjar de Aznalcóllar ${ }^{55}$, que no llegó a realizarse. Aprobándose posteriormente la construcción de un nuevo templo, cuyo proyecto fue encargado al maestro onubense, quien lo presentó el 12 de diciembre de $1782^{56}$. Los cimientos se abrieron en enero de 1783, colocándose solemnemente la primera piedra el día de San Juan de ese año ${ }^{57}$.

53 Solución poco habitual, usada por Pedro de Silva en la torre de San Roque, en cuyo cuerpo de campanas se inspira claramente José Álvarez para este de San Bernardo.

54 Sancho Corbacho considera la iglesia de San Bernardo "la última de importancia entre las construidas en la capital con verdadero carácter sevillano" (Antonio SANCHO CORBACHO, Op. cit., p. 255).

55 ACS, Mapas y planos, Leg. 92.

56 Ibídem, Leg. 93.

57 Antonio RENDÓN JURADO: "Aznalcóllar. Acercamiento histórico cultural". Libro en PDF, 1994. 


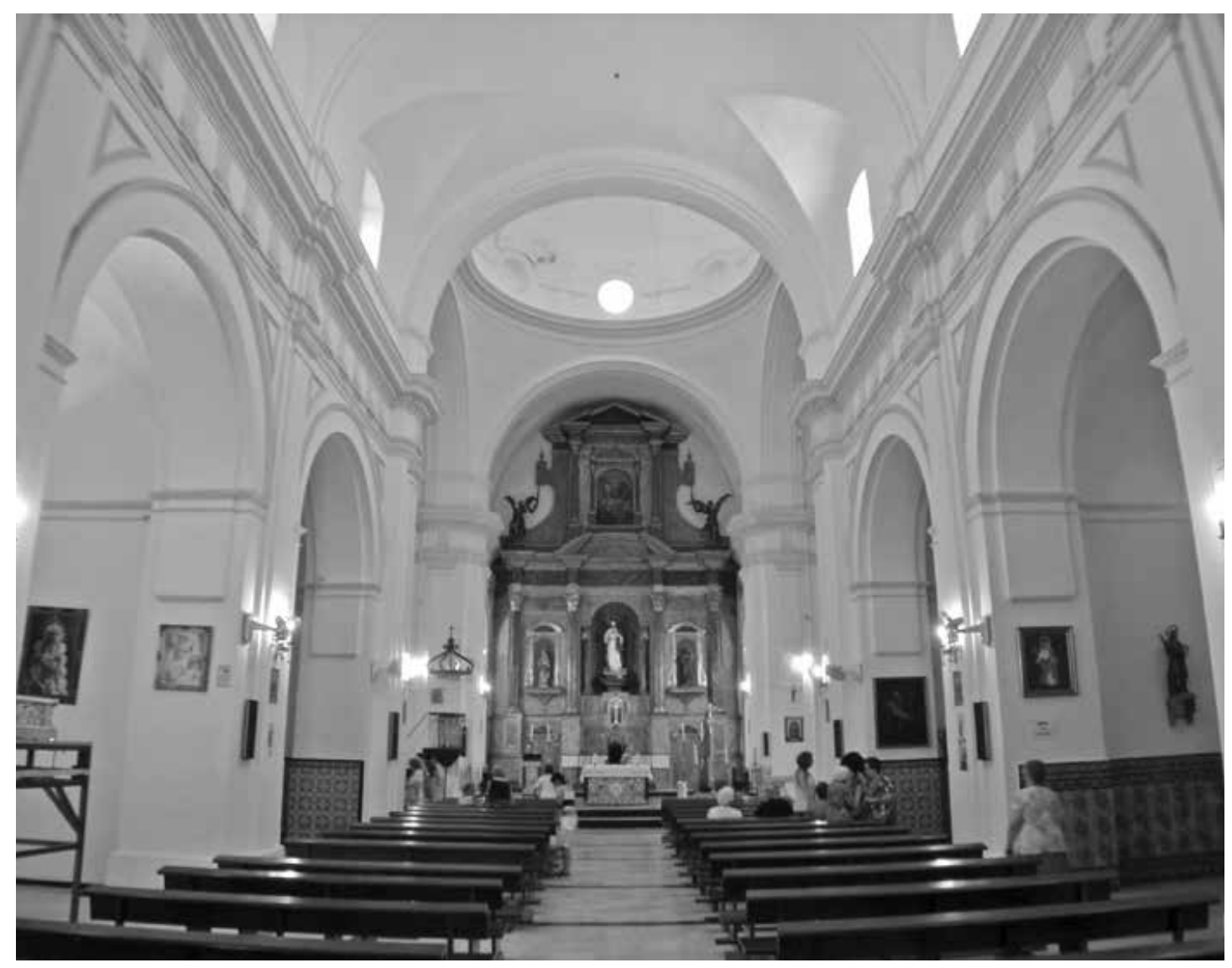

Figura 5. Iglesia de Ntra. Sra. de Consolación de Aznalcóllar, cuyo proyecto fue presentado por José Álvarez el 12 de diciembre de 1782. Los muros de la iglesia, de una nave y tres capillas-hornacinas a cada lado (una de las cuales sirve de acceso al templo), son recorridos por un clasicista arquitrabe dórico completo con friso de triglifos y metopas, al igual que ocurre en San Bernardo. Fotografía del autor.

El templo de Ntra. Sra. de Consolación de Aznalcóllar es de planta rectangular, de una sola nave apilastrada con tres capillas hornacinas entre contrafuertes a cada lado, de las cuales una sirve de acceso, corriendo sobre los arcos de la nave un clasicista arquitrabe dórico completo con friso de triglifos y metopas, como en San Bernardo. Sobre la nave y los brazos del crucero y cabecero se disponen bóvedas de cañón con lunetos, cubriéndose el espacio central con una media naranja provista de óculos. La sacristía y demás servidumbres se sitúan tras la capilla mayor ${ }^{58}$, en tanto que en el cuerpo contiguo a la fachada de los pies se ubican la torre, la tribuna para el órgano y la capilla bautismal. Como decoración de la iglesia, Álvarez dispone en los arcos de las capillas laterales la imposta, la orla y una figura triangular en las enjutas. En cuanto a la conformación de volúmenes, el escalonamiento de la sección transversal y la elevación de la nave central sobre la batería de capillas hornacinas, permite ubicar ventanas en estos paños murales sobresalientes en

58 Originalmente estaban previstas en la gualdera de la epístola, siendo modificada su ubicación gracias al cambio de emplazamiento de la iglesia. 
altura, posibilitando así la entrada directa de la luz a la nave. De esta manera, las piezas sobresalientes del templo en altura -nave, brazos del crucero y capilla mayor-, coronados por el trasdós octogonal de la media naranja, forman la tradicional cruz volumétrica. Todos los elementos quedan cubiertos con faldones de teja, a dos aguas la nave, que conforma un hastial triangular en la fachada de los pies, y los brazos del crucero y la capilla mayor, mientras que la cúpula se cubre con cubierta ochavada contracurvada de teja. Las piezas de menor altura, baterías de capillas hornacinas, se tejan con faldones a un agua, ocultos a la fachada por los volúmenes de la torre y la capilla bautismal, sobresaliendo los estribos, de ondulados remates similares a los de la inacabada iglesia de Castaño del Robledo, en las líneas de carga transversales de la nave. La sacristía y resto de servidumbres se cubren también con faldones de teja a un agua. Como elemento habitual en las iglesias de José Álvarez, un pretil remata en fachada las gualderas de las capillas hornacinas.

En la iglesia se abren puertas a los pies y a los laterales entre las capillas hornacinas, cerradas con medios puntos, ornamentadas con portadas apilastradas de orden dórico ${ }^{59}$. Mucho más monumental la de los pies, en cuyo primer cuerpo dos pares de columnas dóricas sobre pedestales flanquean la puerta soportando un entablamento con triglifos y metopas. En el segundo, dos columnillas jónicas con pedestales enmarcan una labrada y barroquista hornacina ${ }^{60}$, quedando rematado el conjunto, de indudable aspecto clasicista, con un frontón triangular que remarca el hastial.

En cuanto a la torre, provista de dos balcones y un óculo, se sitúa en la fachada de los pies, en el lateral del evangelio, repitiendo básicamente el mismo esquema de caña de planta cuadrada de altura igual a la del caballete de la nave, ubicándose sobre ella el cuerpo de campanas, con un hueco por fachada cerrado por un medio punto. Una pilastra a cada lado de éste, de orden dórico y entablamento con triglifos y metopas, disponiéndose gruesos baquetones en las esquinas a modo de semicolumnas. Finalizando dicho cuerpo con un banco también cuadrado, sobre el que se disponen los típicos jarrones vidriados. La torre queda rematada con un rebanco ochavado sobre el que se apoya el característico chapitel piramidal revestido con cerámica vidriada. Cerrando el lado de la epístola y equilibrando la fachada principal, el volumen que aloja la capilla bautismal se eleva hasta la cornisa de la nave, coronándose por una pieza de planta ochavada de cuatro cuerpos y remate vidriado.

59 La del evangelio presenta frontón partido y jambas de perfil ondulado, hallándose tapiada en la actualidad la de la epístola, rematada con frontón triangular.

${ }_{60}$ Probablemente diseñada por Antonio de Figueroa (Antonio SANCHO CORBACHO, Op. cit., p. 256). 


\section{4. ÚLTIMAS REALIZACIONES. LA IGLESIA PARROQUIAL DE LINARES DE LA SIERRA, DESCONOCIDA OBRA DE JOSÉ ÁLVAREZ. TESTAMENTO DEL MAESTRO Y LA EPIDEMIA DE 1800}

Entre 1776 y 1791, José Álvarez acomete la reforma de la antigua iglesia mudéjar de Villanueva del Ariscal, promovida por el cardenal Francisco Javier Delgado y Venegas, hijo de la villa y arzobispo de la diócesis hispalense entre 1776 y 1781. Quedando documentado su nombre en 1784: "en 27 de abril de 1784 tomó razón de un Libramiento del Señor Subcolector de 220 reales de vellón a favor del Maestro Josef Albarez por la visita y Plan de la Obra de la Yglesia de Villanueva del Ariscal" y el 12 de mayo de 1791, con motivo de un libramiento por el que "pagó dicho Depositario $D^{n}$ Juan José Rabel de los caudales del Expolio del Eminentísimo Señor Cardenal Delgado a D. Josef Albarez Maestro mayor de Alarife de la S ${ }^{\text {ta }}$ Yglesia en virtud de recibo de este Dos mil Doscientos $R^{s}$ de vellon que del Señor Colector General en Orden de 6 del corriente le mandó dar en remuneración del trabajo y tareas que impuso en la Obra de la Yglesia de Villanueva del Ariscal"61.

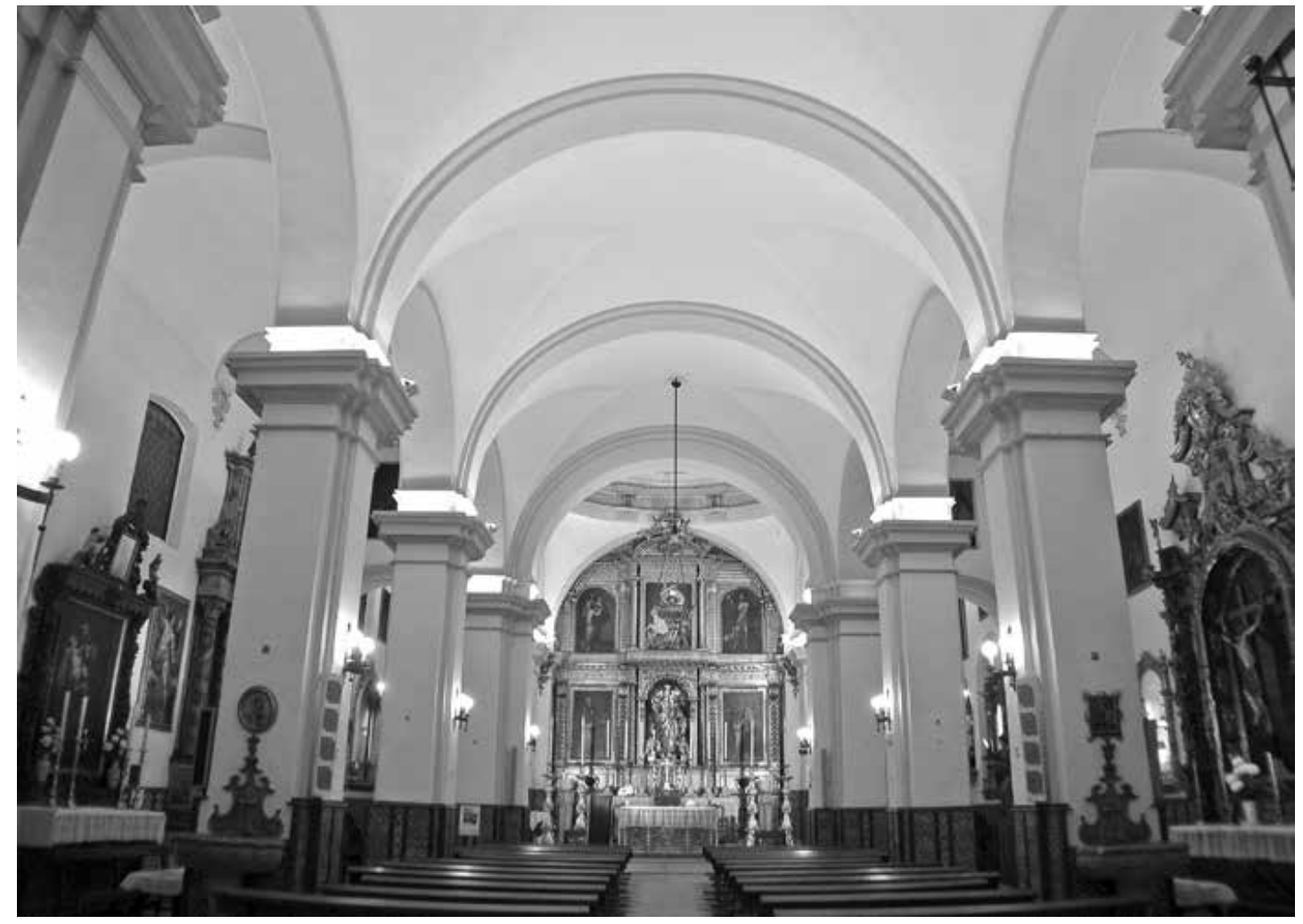

Figura 6. Iglesia de Ntra. Sra. de las Nieves deVillanueva del Ariscal, en la que José Álvarez transformó el primitivo templo mudéjar en una iglesia de salón gracias al patrocinio del cardenal Francisco Javier Delgado y Venegas, hijo de la villa. Las obras se iniciaron en 1776, dándose por finalizadas en 1791. Fotografía del autor.

61 Rafael MARTÍNEZ BUENO:“Obras y reformas en la iglesia parroquial de Villanueva del Ariscal durante el siglo XVIII", XI Semana cultural Santiago 93, Villanueva del Ariscal, 1993. 
La reforma ejecutada por Álvarez resulta sumamente interesante, pues transforma el viejo templo mudéjar del tipo torre-fachada en una iglesia de salón de aspecto interior clasicista, abovedando las naves con cañones, de medio punto con lunetos en la nave central y rebajados en las laterales, e introduciendo algún elemento barroquista, como los pinjantes que cuelgan de los arcos fajones. El maestro dota a la iglesia de una cúpula sobre la capilla mayor, trasdosada en una ochava cubierta con teja sobre los característicos contracurvados faldones, así como adosa a los pies del templo, donde se encontraba la portada principal, una pieza prismática en la que se ubica el coro, cobijado con bóveda de cañón y en cuyo frente se abre un óculo ${ }^{62}$.

José Álvarez también intervendría en la reforma de la torre, dotándola de un nuevo y sobrio cuerpo de campanas cúbico, rematado por un chapitel inspirado en el de San Roque de Sevilla, pero más simple, fechado en 1776.

El último ejemplo representativo de los templos parroquiales trazados y construidos por José Álvarez es el de San Juan Bautista de Linares de la Sierra, que se documenta aquí por vez primera como obra del maestro onubense.

El 19 de diciembre de 1782 principiaron los autos por parte de la fábrica parroquial, cuya iglesia "se hallaba enteramente Ruinosa, de forma que era necesario construirla de nuevo, porque sus cimientos se hallaban de mala calidad, como por su techumbre y Bobeda de la Capilla mayor amenazaban proxima Ruina"63.

Se ordenó a José Álvarez hacer el reconocimiento de las obras precisas y urgentes que necesitaba la iglesia y estudiar su posible ampliación respecto del vecindario que tenía. El maestro prestó declaración el 22 de mayo de 1783, informando de la buena calidad de las gualderas, fachada de los pies, torre y pilares que dividen las tres naves de la primitiva iglesia, si bien sería preciso reconstruir toda su techumbre y la capilla mayor. Aún así, el templo resultaría insuficiente para el vecindario, por lo que se resolvió a formar plano, representando con el color sombra oscuro "la cituazion de la Yga que oy existe, la que se compone de tres Naves, Capilla maior, Bautisterio, Sacristia y Lugar comun", mientras con el color amarillo reflejaba la nueva ampliación proyectada, "aprovechando de sus Muros lo demostrado con el dicho de Carmin". Álvarez planteó una iglesia de una nave y capillas hornacinas, de 25 varas de longitud y 10 de latitud de ámbito libre, "formando el testero de la nueva Capilla maior a la tirantez de la Pared del Porche que mira ael lado del Oriente", con sacristía, cuarto taller, osario y lugar común. Las gualderas del templo primitivo lo serían ahora del nuevo, que mantendría su misma anchura de fuera a fuera, 16 varas y media, conservándose igualmente el hastial de los pies. En cuanto a la torre, de moderna aunque tosca construcción, había que darle más altura, debiendo construirse un nuevo cuerpo de campanas

62 Esta pieza se inspira claramente en la capilla saliente de la nave de la epístola de la iglesia de Manzanilla, obra que supervisó Álvarez entre 1782 y 1783.

63 ADH, Linares de la Sierra 1, Justicia, No 1-4 (1782-1787), Fol. 1r (La imposición de tributo en AHPS, FPN, Of. 19, Libro $2^{\circ}$ de 1790, Sign. 13186, Registro 6). 


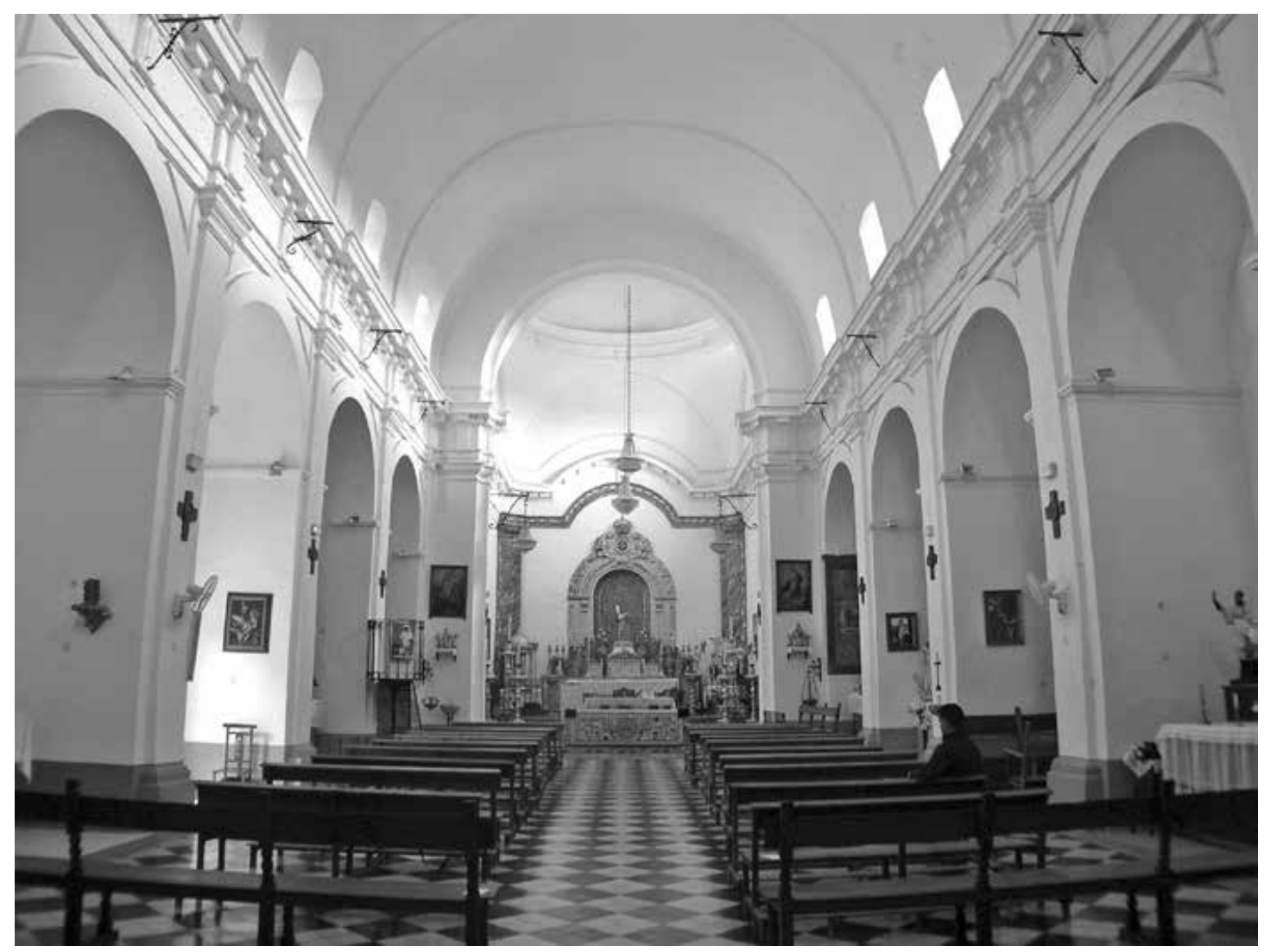

Figura 7. Iglesia de S. Juan Bautista de Linares de la Sierra, de cinco capillas-hornacinas por banda, desprovista de crucero, cuya capilla mayor se abre directamente a la única y alargada nave. José Álvarez presentó su plano y condiciones el 22 de mayo de 1783, un mes después de haber proyectado, con las mismas características tipológicas, el nuevo templo de Santa Ana la Real. No se remataría hasta 1843. Fotografía del autor.

con arreglo al orden toscano, rematado con el tradicional chapitel ochavado. José Álvarez valoró las obras en 133.000 reales de vellón ${ }^{64}$, obteniendo el proyecto licencia el 15 de marzo de 1784.

Se trata de una iglesia de alargada planta rectangular, sin crucero, cuya única nave está cubierta mediante bóveda de cañón con arcos fajones, y capillas hornacinas con la habitual articulación de pilastras dóricas y entablamento completo con friso de triglifos característico de José Álvarez, que ubica el baptisterio y la torre a los pies. La capilla mayor, de planta cuadrada, se abre directamente a la nave, cobijándola una media naranja, en tanto que dos ventanales la iluminan lateralmente. Sacristía y demás servidumbres se disponen simétricamente a ambos lados de la capilla mayor, saliendo de los límites de la planta rectangular, recibiendo el templo la luz natural a través de los cinco pares de ventanas abiertas en la bóveda de cañon de la nave. La iglesia presenta tres portadas, en la principal de las cuales, situada a los pies, dos pilastras dóricas sostienen un sencillo entablamento con triglifos y frontón recto roto. En el ático,

64 Ibídem, Fol. 8r-13r. El plano se ha perdido. 
otras dos pilastritas flanquean una hornacina con el santo titular, bajo un simple entablamento cuyos remates enmarcan al óculo central. En la sencilla portada lateral del evangelio, dos semicolumnas dóricas que enmarcan el vano de medio punto, soportan un entablamento con triglifos, resultando algo más esquemática la de la epístola ${ }^{65}$.

En cuanto a la formalización exterior del templo, se produce la característica jerarquización volumétrica de las diferentes piezas, sobresaliendo la nave respecto de la batería de capillas hornacinas, al igual que en Aznalcóllar, para permitir la apertura de huecos de iluminación en ella. Cubriéndose todo el edificio con tejado, a dos aguas el cuerpo de iglesia y a uno las capillas hornacinas y piezas colaterales a la capilla mayor, siendo éstas las menos elevadas en altura. El hermoso volumen cuadrangular de la capilla mayor se eleva por encima de los aleros de la nave, trasdosándose entonces en planta ochavada con cubierta tejada de contracurvado perfil que sobrepasa la cumbrera de la nave. Como decoración exterior, huecos cegados se recortan en los frentes de los cuerpos de capillas hornacinas, haciendo juego con los vanos de la nave. Ubicada en el lado de la epístola, junto al hastial triangular de fachada, la torre presenta las características comunes del elemento tipo, aunque la caña se eleva por encima de la cumbrera de la nave. El chapitel piramidal ochavado y el cuerpo de campanas son los tradicionales, si bien éste presenta como rasgo ornamental novedoso unas impostas en el centro de las pilastras pareadas que flanquean a los huecos. Al lado del evangelio, el volumen de la capilla bautismal se eleva para continuar la cubierta de la nave, equilibrando la fachada principal con la inserción de un balcón simétrico al dispuesto en la caña de la torre. Las obras se demoraron extraordinariamente en el tiempo, rematándose al parecer en 1843.

Hay que decir finalmente que el proyecto de José Álvarez para la iglesia parroquial de Linares de la Sierra, de una sola nave y capillas hornacinas desprovista de crucero, es similar al presentado por el maestro un mes antes, el día 15 de abril de 1783, para la villa de Santa Ana la Real, pero con un tramo más de capillas ${ }^{66}$.

65 Sobre el adorno de las portadas, en su informe de 17.Ago.1785, Fernando Rosales reconoció que se hallaba "Excedido solo en la construccion de las medias muestras de columnas, bien es que son de tosco", y preguntando al respecto al maestro ejecutor, Alonso Sánchez, éste respondió "que con motivo de tener que hazer en aquel sitio un Estrivo de media vara de Salida, tuvo por combeniente el construirla para que no se quedase la referida Puerta encajonada y tuviese algun adorno, yendo siempre areglado al Orden Dorico, y en la Opuesta que mira al Norte al Orden toscano, conforme se lo previenen las condiciones, y que si se le huviera dado Alsao, se hubiera areglado justamente de un todo". Ibídem, Fol. 123r-124r.

66 El proyecto desprovisto de crucero de Santa Ana la Real, solución tomada de la tipología eclesial mudéjar, hubo de ser ampliado durante el replanteo de su cimentación a efectos de dotar de más capacidad al templo, añadiéndole el 15.Nov.1784 el crucero Antonio de Figueroa, quien dirigiría la obra hasta la altura de cornisas. El 28 de febrero de 1793 Fernando Rosales realizaría la declaración de cumplido (ADH, Santa Ana la Real, Justicia, Clase 2a , Leg. 582. Y ACS, FC, Contaduría, Sign. 11667, Exp. 13). 
No sería ese el último proyecto de templo de una nave y capillas hornacinas de José Álvarez, dando poco después las trazas para Campofrío, villa también de la Sierra de Aracena, aunque serían reformadas, como se verá, por Antonio de Figueroa, que hizo además todas las visitas de obra ${ }^{67}$.

El 26 de mayo de 1774, el procurador de fábricas solicita la visita del maestro mayor a Campofrío para comprobar el estado de las cubiertas del templo, tocando en turno a Antonio de Figueroa, quien no pudo desplazarse a dicha villa por encontrarse enfermo, siendo sustituido por Pedro de Silva ${ }^{68}$.

El 16 de julio, Silva presentó las trazas para edificar nueva iglesia de tres naves, pilares cruciformes y cubiertas de madera, parecidas a las que dio doce años antes para San Sebastián de Marchena, valorando su coste en 160.000 reales $^{69}$. El proyecto no sería aprobado, quedando paralizadas las actuaciones.

Nueve años después volvió a ser requerida la presencia del maestro mayor a Campofrío, girando visita José Álvarez, quien informaba el 14 de agosto de 1783 "que construyendo una nave de capillas hornacinas al traves y buscando el medio de la longitud de la que hoy existe, quedan una Yglesia de bastante capacidad, de modo que trasladando el altar mayor al frente de la dicha nave nuevamente agregada se forma un crucero sin cabecero lo que es muy util, pues desde qualesquiera parte se apercibe la vista del altar mayor". Álvarez presentó el plano, aunque no las condiciones, para construir una nueva iglesia girada $90^{\circ}$ respecto de la antigua, cuyo nuevo testero lo constituiría la gualdera del evangelio de ésta, al mismo tiempo que se aprovecharía el resto del viejo edificio para ubicar lateralmente la sacristía y otras dependencias del nuevo. La iglesia sería de una sola nave con capillas hornacinas, sin cabecero, media naranja sobre la capilla mayor y crucero, cuyos brazos serían los extremos de la nave antigua, quedando cubierta la nave y el crucero con bóveda de cañón ${ }^{70}$.

La diócesis aprobó el proyecto de Álvarez, comenzando a labrarse los cimientos el 16 de marzo de 1784. El 2 de junio informa dicho maestro que ha pasado a Campofrío para comprobar las zanjas abiertas para los cimientos, dictando ahora las condiciones de la obra. En cuanto a las portadas laterales, dice simplemente que "el ornato de las dos puertas de entrada las que se ejecutarán con soclo, pilastra, capitel, arquitrabe, friso y cornisa, con un frontis y remate de vedrio, con arreglo al orden dorico", no disponiendo el templo de puerta a los pies, donde se ubicará el coro. La nave tendrá 10 varas de ancho y 14 de alto hasta la clave del cañón, especificando respecto de la decoración interior que "este adorno como el

67 Asimismo, su proyecto de 14.Jun.1784 para la reforma y ampliación de la iglesia parroquial de Alosno con una nave y capillas hornacinas, esta vez provisto de crucero, fue completamente modificado por Antonio de Figueroa (16 y 29.Dic.1784) y Fernando Rosales (11.Jun.1785).

68 ADH, Justicia, Ordinarios, Fábrica, Caja 141, Doc. № 3.

69 Ibídem, Fol. 4r-5v.

70 Ibídem, Fol. 12r-15v. Resultando una planta similar a la proyectada por José Álvarez en mayo de ese mismo año para la nueva iglesia de Linares de la Sierra, que venía siendo atribuída a Fernando Rosales. 
de la cornisa y banquillo se distribuirá con respecto al orden dorico, omitiendo en las pilastras, capiteles y arquitrabe sin otra cosa mas que un collarin con su friso". En las esquinas de los pies se ubicarán la capilla bautismal y la torre, cuya "caña o cuerpo basto quede reducido a su cuadrado, el que se continuará hasta el alto de las quince varas que se ha dicho ha de quedar el cañon de la nueva extension, para despues sentar la imposta y seguir con el cuerpo de campanas"71. A partir de entonces, todas las visitas a esta obra las hará Antonio de Figueroa, por lo que a mi entender, a él se deben los detalles decorativos de la iglesia, incluyendo las portadas (ya se ha visto lo escueto de sus condiciones). Más aún teniendo en cuenta que dicho maestro iba a modificar sustancialmente el encaje de la planta de Álvarez en la iglesia antigua.

Así, el 15 de julio de 1785, Antonio de Figueroa informa que ha visitado las obras para disponer cómo debían proseguir. Había comprobado los cimientos, que estaban bien ejecutados, viendo la conveniencia de "formar $y$ presentar nuevo plano, el que va ejecutado con todo arreglo a el anterior del que dio principio a esta obra, asi en las dimensiones de gruesos de muros, latitud de nave y distribucion de capillas hornacinas". Sin embargo, discrepaba de la solución sin cabecero de Álvarez, ya que "habiendo hecho el concepto que la longitud de la nave de la dicha antigua Yglesia quedara de crucero, con el conocimiento de la crecida reparacion que era necesario ejecutar para este fin, como era embutir medias muestras en los rincones y lineas de paredes para cuya operacion era forzoso cajearlas y de ella resultaria ser indispensable demoler dichas paredes por ser de mamposteria...()...a lo que se agregaba la ejecucion de formeros y bovedas vaidas para los cubiertos de dicho crucero"72, presentando Figueroa nuevo plano con la inclusión de cabecero y crucero independiente de la obra antigua, para que "ejecutandose esta obra con todo arreglo a los gruesos de muros que en el van demarcados y con orden a las condiciones que se hallan en estos autos...()...presentados por Jose Alvarez, maestro mayor del Ylustrisimo Cabildo de la Santa y Patriarcal Yglesia de esta ciudad, sin la menor duda se concluirá la expresada obra con toda seguridad"73. Figueroa mantendría el resto de las condiciones dadas por José Álvarez "correspondientes a el arte, asi en la distribucion de materiales, adornos de arquitectura (las que van ceñidas solo a lo muy preciso) como a las alturas del edificio", siendo indudable que a él se deben los detalles ornamentales del templo, incluidas las portadas, que sólo quedaron apuntados escuetamente por Álvarez. Las obras fueron valoradas en 172.000 reales de vellón, advirtiendo Figueroa que "si en la ejecucion

71 Ibídem, Fol. 46r-48v.

72 Con esta modificación se ganaban espacios para dependencias, además de que no habría que ejecutar la delicada operación de recrecer bastante los viejos muros de la antigua iglesia para formar los hastiales del nuevo crucero.

73 Esta decisiva modificación del proyecto de José Álvarez por parte de Antonio de Figueroa no había sido correctamente explicada. Véase José María SÁNCHEZ SÁNCHEZ: “El proceso constructivo de la iglesia de San Miguel Arcángel de Campofrío", en XXIII Jornadas del Patrimonio de la comarca de la Sierra, Campofrío (Huelva). Diputación Provincial de Huelva, 2010, p. 53-98. 
hubiere algun exceso en lo adornativo, se da por supuesto se aumentará el gasto y supercrecerá la cantidad del citado aprecio"74.

A partir de entonces se haría cargo de las obras Antonio de Figueroa, que giró cinco visitas más a Campofrío, dándolas por concluidas en su informe de 7 de abril de $1791^{75}$.

Aunque Sancho Corbacho da la noticia de que José Álvarez fue nombrado maestro mayor del Arzobispado de Sevilla el 17 de enero de $1782^{76}$, debió tratarse de un nombramiento interino, pues el 8 de noviembre de 1784, con motivo de las obras de la nueva iglesia de Castaño del Robledo, declara Antonio de Figueroa ser "Jph. Alvarez, Maestro Maior del Yllmo. Cavildo de la $S^{\text {ta }}$. y Patriarcal Yga . de esta Ciudad y de las de fabrica de este Arzobispado (Sede vacante)"'77. Si bien al principio tuvieron sus más y sus menos, el maestro onubense mantendría finalmente buena relación con Figueroa, colaborando ambos en varios proyectos (Algodonales, Aznalcóllar, etc.) y ponderando mutuamente los méritos del colega. Por ejemplo, el 26 de abril de 1784, al informar sobre su visita a las obras de la torre de San Pedro de Carmona, proyectada por Antonio de Figueroa, José Álvarez reconoce que "es ciertto tiene alguna mas obra en sus adornos pero todos son uttiles por su buen artte y simettria que guarda, pues es ciertto habrá pocas torres en el Arzobispado como ella, y con la solidez correspondiente $e^{\prime \prime 78}$.

Otras intervenciones y propuestas ejecutadas del maestro onubense no citadas anteriormente fueron su proyecto de ampliación de la sacristía y otras dependencias en Santa María de la Mesa de Utrera (8.Jun.1776), informe de reparación de cubiertas y bóvedas de la iglesia de Jabugo (12.Ago.1776), proyecto de nuevo campanario y remate de la torre de San Pedro de Sanlúcar la Mayor (8.Sep.1776), proyecto de la nueva sacristía de la parroquial de Alcalá del Río (16. Sep.1782), condiciones para la reparación de la parroquial de Castilleja del Campo (20.Dic.1782), ampliación del cuerpo de iglesia por los pies y buhardillas de la parroquia de San Juan del Puerto (21.Dic.1782), proyecto de ampliación mediante realización de crucero en la de Cabezas Rubias (7.Jul.1783), proyecto de nueva sacristía para la iglesia de Cantillana (22.Jul.1783), condiciones para construir la tribuna de los pies de la iglesia de Torre Alháquime (19.Ago.1783), supervisión del comienzo del derribo de la iglesia ecijana de San Juan (12.Sep.1783), proyecto de reforma y ampliación de sacristía y servidumbres de la iglesia de Cartaya (8.Oct.1783), proyectos de casas-cillas en Chipiona (12.Jul.1790) y Rota (1790), aprecio de la Hacienda de Doña Ana en Dos Hermanas (16.Ene.1795) y parecer sobre la ubicación de las nuevas bóvedas de enterramientos de la iglesia

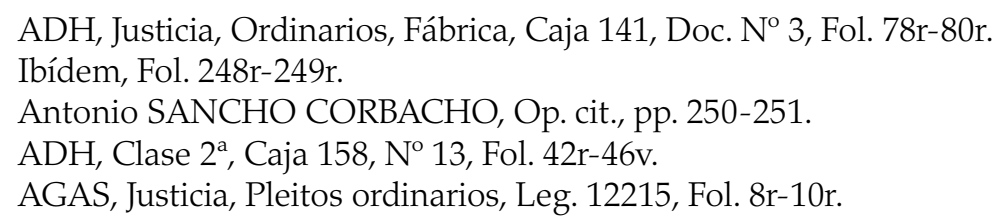


de San Bartolomé de Sevilla (1.May.1795), última intervención documentada del maestro en edificios eclesiásticos, aunque continuaría evacuando pareceres y aprecios de propiedades al menos hasta $1797^{79}$.

Como proyectos no realizados cabe destacar una casa con horno de pan en la calle Mangagabán (actual Rocío) de Sevilla (28.Ene.1784) y la ampliación de la primitiva iglesia parroquial de Castaño del Robledo (6.May.1784), conservándose en ambos casos los planos originales de José Álvarez.

En cuanto a la última parte de su biografía, la localización del inédito testamento del maestro ofrece desconocidos datos sobre su vida profesional y familiar, así como sobre sus parientes más inmediatos.

Otorgado en Sevilla el 17 de febrero de 1793 ante el notario Manuel Montero de Espinosa ${ }^{80}$, el documento comienza declarando la viudedad de " $D^{n}$ José Albarez...(.)...Maestro Maior que soy de las Obras de la $S^{\text {ta }} Y g^{a}$ Cattedral de estta Ciudad", eludiendo citar la maestría mayor del Arzobispado, lo cual podría refrendar el carácter oficioso de su nombramiento al frente de las obras diocesanas. Habiendo afirmado gozar de buena salud y después de la habitual protestación de fe y las mandas acostumbradas, el maestro expone que su mujer falleció hacia 1790, tras lo cual otorgó su testamento. Legando a continuación a $\mathrm{D}^{\mathrm{a}}$. Josefa Basosaba, el ama que le asistía "de muchos años a estta partte cuidandome con basttantte Caridad atencion y Cariño", todo el menaje y el oro de la casa.

José Álvarez nombra por sus albaceas al canónigo D. Juan José de Salcedo, a la referida ama y a D. Pedro Valencia, dejando a su elección los detalles de su entierro y encomendándoles dividir sus bienes en tres partes iguales, destinando la primera de ellas a "decir Misas por mi Alma la de mi Muger la de sus Padres y mios y demas que padecen en penas del Purgattorio". La segunda se le entregará a $\mathrm{D}^{\mathrm{a}}$. Josefa Basosaba, en tanto la tercera se ha de repartir equitativamente entre sus hermanas $\mathrm{D}^{\mathrm{a}}$. María, $\mathrm{D}^{\mathrm{a}}$. Juana y $\mathrm{D}^{\mathrm{a}}$. Nicolasa y su hermano D. Juan Álvarez, "por no tener hijos ni herederos forsosos que conforme a derecho me deban heredar".

Finalmente, el maestro expone que los herederos de su antecesor en el cargo (Tomás José Zambrano) habían recibido durante catorce años una pensión anual de cincuenta ducados de vellón (550 reales), suplicando "con el respetto devido a los Yltmos Sres Dean Cavildo de dicha $S^{\text {ta }} Y g^{a \prime \prime}$, que asignasen para sus hermanas la cantidad que les pareciere, "respetto de la pobresa que tienen".

79 A José Álvarez se le atribuye también el proyecto para concluir la iglesia parroquial de Chipiona (18.Nov.1783).Véase José Ramón BARROS CANEDA:“La iglesia parroquial de Nª. Sra. de la O de Chipiona", Laboratorio de Arte, no 13, Sevilla, 2000, p. 329-339. Su último trabajo profesional documentado es de fecha 4.Feb.1797 y es el aprecio que hizo en Sevilla de cuatro casas junto con el maestro mayor de carpintería Agustín Trujillo. AHPS, FPN, Año 1797, Leg. 10369, Fol. 170v-172v (se repite en los Fol. 262v-264v, 322r-323v y 420v-422r). Pub. en Francisco Sabas ROS GONZÁLEZ: "Noticias de escultura (1781-1800)", Fuentes para la historia del arte andaluz XIX (Dir. Jesús M. PALOMERO PÁRAMO). Sevilla, 1999, p. 756.

80 AHPS, FPN, Of. 17, Libro $1^{\circ}$ de 1793, Fol. 235r-v, Leg. 11256. Inédito. 
Siete años después, el 1 de octubre de 1800, acudiría por última vez al notario a fin de otorgar codicilo, en el que, tras intitularse de nuevo "Maestro mayor de obras de Albañileria de la Santta Yga Catedral de esta Ciudad de Sevilla" y declarar su buen estado de salud, nombra por sus albaceas definitivos a los canónigos D. Antonio de Armenta y Góngora y al citado D. Juan José de Salcedo, firmando el documento ${ }^{81}$.

Sin embargo, José Álvarez enfermó de inmediato, falleciendo justamente una semana más tarde de otorgar su codicilo, a punto de cumplir setenta y siete años, víctima de la terrible epidemia de fiebre amarilla que acabó prácticamente con el veinte por ciento de la población de la ciudad hispalense82. De esta manera tan cruel llegaba a su fin la vida de uno de los maestros más prolíficos y representativos de la arquitectura sevillana del XVIII, cuya desaparición, coincidente con el cambio de centuria, significaría también el final de la longeva tradición constructiva barroca de la región. Su entierro tuvo lugar el día siguiente en la parroquia de la Magdalena ${ }^{82}$.

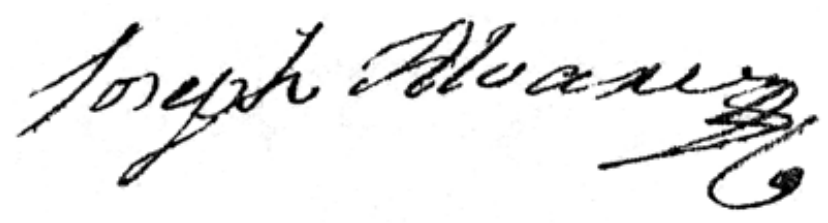

Figura 8. Firma de José Álvarez. 1779.

81 AHPS, FPN, Of. 17, Año 1800, Fol. 791r-v, Leg. 11265. Inédito. La plasmación de su firma al pie del codicilo ratifica su buen estado de salud.

82 APSMMS, Libro 10 de entierros, Fol. 37r-v, 9.Oct.1800. Inédito:

"En Nueve de Octe de mil y ochocientos se enterro en el Campo Sto el cadaver de D" Josef Alvarez Viudo de $D^{a}$ Maria Sanguino vivia Calle de la Muela testo ante $D^{n}$ Manuel Montero y espinosa tuvo trasnocho y entierro y murio del contagio". 


\title{
APÉNDICE DOCUMENTAL
}

\section{DOCUMENTO 1 \\ JOSÉ ÁLVAREZ PRESENTA AL CABILDO EL PLANO HORIZONTAL Y ALZADO DE LA NUEVA IGLESIA DE SAN BERNARDO. SEVILLA, 10.MAY.1780. INÉDITO}

\author{
ACS, FC, Contaduría, Leg. 12316, Exp. 1
}

\begin{abstract}
Digo yo Josef Albarez Maestro Maior de Obras del Yllmo Sor Dean y Cavildo de estta Sta $Y_{g^{a}}$ que en cumplimiento de lo mandado por sus $S^{\text {rias }}$ los $S^{\text {res }}$ comicionados por dicho $S^{r}$ Yllmo para la obra de la $Y g^{a}$ Parroquial de $S^{r} S^{n}$ Bernardo, e vistto y reconocido y medido el sittio de las Casas que fueron de Patronatto y con el que ocupa la $Y g^{a}$ que es oy e modelado planos orisonttal y alsado para la construccion de la Yga tomando el sittio mas adequado para que lo sobrantte de el quede a la plaza y Calle de la Delanttera de Toda la fachada, y asi mismo ba trasado casa para el padre Cura y ministros como son sachristtan y monasillos todo segun lo manifiestta los planos que acompañan estta relazion quedando la $Y g^{a}$ de Tres Naves attiranttada su fachada con los muros de la $R^{l}$ fundicion, esto es la del estado del lado del evangelio, y la de los pies de la $Y_{g^{a}}$ a la Calle que estta asia la enrramadilla, que attirantte las casas del pattronatto, y en estta con la fachada pral queda la de la Casa del Padre Cura teniendo su uso por dicha calle como tambien la enttrada de la Yga que forma el Porche tambien por dicha Calle quedandole a estta capacidad para Carrettas sin que molestten o padesca el porche, por lo amplia que queda por el mucho sittio que ay pues ay para Yga y Casa, y queda sobrantte para Calles quedandole a la dicha Yga quarentta baras de longittud y Veintte de lattittud sin incluir los muros ni grueso de postteles de tres naves la mayor de 9 varas de ancho y las menores de sinco, como el plano lo demuestra, asi mismo el Cruzero, Capilla maior y presvitterio que queda a su espalda la Capilla del SS mo teniendo su uso por la nave menor del lado del Evangelio por no tocarle a dicha capilla del SS $S^{m o}$ mas que es a la pared guardera que divide oy la Yga y dicha Capilla, por ser el testtero el presvitterio y por dicha razon es indispensable consttruir de nuevo dicha pared al mismo tiempo que se executte lo demas que Corresponde a la Yglesia, y en dichos terminos, determinandolo VS puede construirse la referida Yg $g^{a}$ siendo cubiertta de bobedas tabicadas las naves menores y colgadisos de madera que cubran las bobedas, y la maior con armadura y cañon enlisttonado o tabicado, y asimismo la media Naranja a de ser una boveda baida que la cubra a conttinuacion la armadura de la nave Maior por evittar costtos de media Naranja y Cuerpo de luzes que esttas las a de tomar por las paredes comunes del Cruzero, y asimismo el Cuerpo de Yga $y$ en dichos terminos aze las condiciones siempre que VS dettermine su consttruccion, y echa la quentta por menudo del costto de la referida obra en los terminos que llevo relacionados le e sacado a la suma asiende a quinienttos mill $R^{s}$ de $v^{n} y$ haviendo de construirse bobedas subtterraneas solo en la Capilla mayor se aumentta su costto a Veintte mil $R^{s}$ de $v^{n}$ mas de dicha canttidad que las dos parttidas componen quinienttos veintte mill, es quantto tengo que Declarar sobre el dicho partticular intterin manda VS octra cosa que tenga por mas arreglado; Dicha Diliga é executtado bien y fielmentte según mi yntteligencia y para que constte lo firmo bajo de juramento que haze en caso necesario Sevilla y Mayo dies de mill Settez ochentta =
\end{abstract}




\title{
DOCUMENTO 2
}

\section{JOSÉ ÁLVAREZ OTORGA TESTAMENTO. SEVILLA, 17.FEB.1793. INÉDITO}

\author{
AHPS, FPN, Of. 17, Libro $1^{\circ}$ del año 1793, Fol. 235r-v, Sign. 11256
}

En el Nombre de Dios Amen = Sepan quantos estta cartta de mi Testtam ${ }^{\text {tto }}$ y ultima volunttad vieren como yo $D^{n}$ José Albarez de esttado viudo de $D^{a} M^{a}$ Visenta Sanguino y Maestro Maior que soy de las Obras de la $S^{t a} Y g^{a}$ Cattedral de estta Ciudad vez de ella Calle de la Muela Collacion de $S^{\text {ta }} M^{a}$ Magna = Estando con salud de que doy infinitas gracias a Dios Nro $S^{r}$ y en mi cumplida y buena Mema, tal qual su Divina Magesttad ha sido servido de me querer dar y creyendo como firme y verdaderamente creo el Divino Misterio de la $S^{m a}$ Trinidad Padre Hijo y Espirittu $S^{\text {tto }}$ tres personas Realmente distinttas y un solo Dios verdadero y en ttodo lo demas que tiene cree y Confiesa Ntra $S^{\text {ta }}$ Madre Yga cattolica Apostolica Romana en cuia fee y creencia he vivido y protextto vivir y morir como fiel y Cattolico christiano que soy y deseando salvar mi Alma y ponerla en Carrera de salvasion = Ottorgo que hago y otorgo este mi testtamentto en la forma y manera sigte

Lo primero Ofrezco y encomiendo mi Alma a Dios Nro Sr que la hizo crio y redimio con el infinito precio de su sangre por lo qual Suplico a S.M. se sirba perdonarla y llebarla a el eterno descanso de su gloria que es el fin para que fue criada y para ello pongo por mi inttercesora y Abogada a la que lo es por Exc ${ }^{a}$ de los Pecadores la virgen $S^{\text {ta }}$ Maria su Querida Madre Ntra concevida en gracia desde su Purisimo Ser $=Y$ quando su Divina Magesttad fuere servido de me llebar de estta presente vida quiero que por mis Albaceas (que despues he de nombrar) se disponga mi funeral = el Abito que a mi Cuerpo se halla de poner = El numero de Acompañados de que se ha de disponer mi Entierro que será en la Yga de mi Parroquia o en la Capilla citio partte o lugar donde se destinare para ello pues todo queda a su eleccion_

Ytt Por lo tocantte a el numero de Misas que se hubieren de mandar decir por mi Alma e inttencion su distribucion y Limosna seran las que señalaren mis Albaceas con arreglo a lo que de derecho asi quedare y de ellas se darán la quartta partte a mi Paroquia para la quartta funeral que le toca_

Ytt Mando que se den a cada una de las Mandas forsosas y acostumbradas en los testtamenttos $S^{\text {tos }}$ Lugares de Jerusalem Niños expositos nombrados de la Cuna Redempcion de Captivos Christianos medio real de medio de Limosna por una vez con lo que las separo de qualquier derecho que puedan tener a mis vienes_

Ytt Declaro que la cittada $D^{a} M^{a}$ Sanguino murio vajo poder para testtar que nos teniamos dado antte el presente ess ${ }^{\text {no }} \mathrm{pp}^{\mathrm{co}}$ nombrandonos por herederos y Albaceas en cuia virttud ottorgué el testtamentto de la suso dicha antte dicho ss $^{\text {no }}$ habra como tres años al que me refiero_

Ytt Prevengo enttro en mi casa y asistencia sirviendome de Ama $D^{a}$ Josefa Basusava de muchos años a estta partte cuidandome con basttantte Caridad atencion y Cariño y quiero que a estta por ninguna persona ni Albacea no se le pida ni tome quentta de todo lo que ha manejado y maneja en dicha mi Casa por la mucha Satisfaccion esperiencia y segun lo que tengo esperimenttado de su buen Obrar y que se estté y pase por lo que boluntariamente dijera la suso dicha sin mas justificacion_

Ytt Es mi bolunttad el dejarle como le dejo a la suso dicha $D^{a}$ Josefa Basusava el omenaje de la Casa y el oro de ella para que lo recoja y se enttregue en lo que demas quedare por hacerle Manda y legado en forma por una vez y le pido me encomiende a Dios_ 
Y para pagar y Cumplir estte mi testtamentto lo que en el dejo y puestto nombro por mis Albaceas testtamenttarios a el $D^{r} D^{n}$ Juan José de Zalcedo Canonigo de la $S^{\text {ta }} Y^{a}$ Catedral de Sevilla y vicittador de los Comb ${ }^{\text {tos }}$ de Monjas y precidentte de la Sala de Examinadores Sinodales = a la dicha Josefa Basusava y a $D^{n}$ Pedro Valencia vecino de estta Ciudad a los quales y a cada uno insolidum les doy ttodo poder Cumplido y de Albaceasgo en forma para que use del cargo de tales aunque sea pasado el tiempo del dro mucho mas y para que entren en mis vienes los recojan hagan Ymbenttariar y apreciar y vender en Almoneda publica o fuera de ella para cumplir mi disposicion pidiendo perciviendo y Cobrando judicial o extrajudicial todas las Cantts de rrs mrs que denttro o fuera de estta Ciudad me toquen y perttenescan se me deban o devieren con quales quiera motibos rasones que sean usando de Ynstrumenttos y papeles ajusttando y liquidando quentas haciendo ajustes combenios transacciones dando recibos Carttas de pago finiquittos Carttas chancelaciones y ottros Ynstrumentos y siendo presiso parecer en juicio anttes quales quiera Tribunales y $S^{\text {res }}$ Jueces poner demandas seguir auttos dar pedimenttos Sacar despachos y hacer las demas diligencias que se ofrescan con qualquier Administrador_

Y Cumplido y pagado que sea estte mi testtamento Mandas y Clausulas en el Conttenidas el remanientte de Caudal de mi quedare, denttro o fuera de estta Ciudad Dinero prendas Ropa Alajas y demas acciones y dros que me toquen y pertenescan en qualquier manera que sea quiero el que por mano de mis Albaceas extrajudicialmente se hagan tres parttes iguales siendo la primera para que por la misma mano de los suso dichos se distribuia y Combiertta el mandar decir Misas por mi Alma la de mi Muger la de sus Padres y mios y demas que padecen en penas del Purgattorio y que se dé por la limosna de cada una sinco rrs $v^{n}$ distribuyendolas en los Comb ${ }^{\text {tos }}$ $Y g^{s}$ y sacerdotes partticulares que les pareciere de quienes recojeran los recibos correspondientes = La segunda partte se le enttregara y dará a la dicha $D^{a}$ Josefa Basusava para que la recoja y disponga de ella libremente para si $=Y$ la tercera y ultima parte se dará y repartirá enttre mis hermanas $D^{a} M^{a}$ Albarez $=D^{a}$ Juana Albarez y $D^{a}$ Nicolasa y $D^{n}$ Juan Albarez = por parttes iguales y disponga cada una la suia en cuia conformidad hago la yntittucion de mi herencia por no tener hijos ni herederos forsosos que conforme a dro me deban heredar_

$Y$ Reboco anulo y doy por ninguno y de ningun valor ni efectto todos y qualesquiera testtamenttos Mandas y Cobdicilos poderes para testtar y otras ultimas disposiciones que anttes que ahora tenga hechas y otorgadas por escritto o de palabra para que ninguna valga ni hagan fee en juicio ni fuera de el sino es estte testtamento que aora hago en el que queda Cumplida mi ultima volunttad y como tal se guarde como en el se contiene en cuio testimonio asi lo ottorgo que es fecha la Cartta en la Ciudad de Sevilla el dia Dies siete del mes de Feb de mil Settecientos nobenta y tres y el otorgante al tiempo de firmar Dijo que mediante que quando havia entrado a ser maestro mayor de la Santa Yglecia havia tenido catorce años de pencion de cinquenta ducados de $v^{n}$ cada uno a los herederos de su antesesor pedia y suplicaba con el respetto devido a los Ylt ${ }^{\text {mos }}$ Sres Dean Cavildo de dicha $S^{\text {ta }} Y g^{a}$ si fuere de su agrado el señalarle a las hermanas del otorgante lo que les pareciera y gustaran o por via de limosna respetto de la pobresa que tienen dichas sus hermanas y en estta forma lo firmó y Yo el ss ${ }^{\text {no }}$ publico doy fe conosco, testigos $D^{n}$ Francisco Galeti, $D^{n}$ Manuel Liberal $D^{n}$ Joachin espino $V^{s}$ Sevilla $=$

Manuel Montero de Espinosa
Josef Alvarez 